\title{
Thin Film Solar Charge Controller: A Research Paper for Commercialization of Thin Film Solar Cell
}

\author{
Mohammad Shariful Islam \\ Dhanmondi R/A, Bangladesh
}

Copyright $@ 2015$ Horizon Research Publishing All rights reserved.

\begin{abstract}
Solar Home System comprise with Solar PV, battery, and solar charge controller. Solar panels convert sunlight energy into electric energy by an electro-chemical process called photovoltaic process. Battery store electrical energy throws chemical reaction between acid and electrode. During discharge, stored chemical energy convert into electrical energy is then use for illumination lamp and running others electrical appliances. Most of cases solar energy consumer use solar energy at evening hours, but it is available in day time. So, it is required to store solar energy into battery. Each battery has certain limit of capacity. Battery lifetime reduces due to overcharging and deep discharging. As battery is very expensive component of solar home system. So, it is essential to protect from over charging and deep discharging. In this case charge controller plays a vital role to protect this battery. A solar charge controller, or charge regulator is similar to the voltage regulator. It regulates the voltage and current coming from the solar panels and going to the battery. Most of batteries are fully charged at 14 to 14.5 volts. On the other hand batteries life time drastically reduces due to discharge over the level of 70 - $80 \%$ DOD; at this discharge level the battery voltage normally goes down to $11.5 \pm 0.2$ volts. The aim of this work is to study design and implementation a thin film solar charge controller for commercialization the thin film solar system. In Bangladesh, all supplier has involved with mono-crystalline solar and poly-crystalline solar, but no one deal with thin film solar system; due to lack of appropriate solar charge controller for solar home system (SHS). Thin film solar system is cheapest than other solar system and its installation accessories are obtainable in the local market to purchase in easy approach.
\end{abstract}

Keywords A design for SHS with PWM function to reduce static power loss

\section{Introduction}

Day by day it is increasing the energy demand in the world, but resource is very limited. Everyone try to develop some things to use limited resource which are available in the world. Energy crisis, these problems are not mew problem for us, every nation, and every country is trying to solve the problems in the various ways such as solar energy, oil, electricity, gas etc. Maximum peoples are tried to solve these problems to use conventional energy, but some peoples are tried to solve these problem to focus the alternative ways; they main concern to save the environment to meet our energy demand; they are mainly focus on the renewable energy.

In our hand, there are available lots of renewable energy source such as solar energy, wind energy, Geo-thermal energy, bio-gas energy etc. I am one of them who is tried to solve these problems to save our environment. I am mainly focusing the solar energy field. We get lots of light energy form the sun that why it is very easy to convert the light.

In Bangladesh, many people are introducing with solar energy and they deal in mono-crystalline solar cell and poly-crystalline solar cells because of its all accessories are available in our local market or international market. But, these solar cells are not cheaper rather than thin film solar cell. There have some issues about thin film solar cell such as nonstandard solar modules, lack of thin film solar charge controller etc.

Government of Bangladesh gives priority to increase solar energy use. Government encouraging people to increase use solar energy. Many NGO's are working to support in case of solar energy use.

\subsection{Objective}

Charge controller takes part in very significant role in solar home system. Solar home system efficiency, lifetime, and performance mostly depend on solar charge controller. Objective of this work as follows -

- Introduce with new thin film solar charge controller.

- Study different types of charge controller available in market.

- $\quad$ Find out the drawback of available charge controller.

- Analysis of drawback of available charge controller.

- Introduce new charge controller to use thin film solar system. 
- Try to overcome of available charge controller.

- Create cost effective charge controller.

- Popular thin film solar energy to all.

- Play role minimize electric energy crisis

- Inspire people to use thin film solar energy.

- Establish a reference in the local market with this charge controller.

\subsection{Background}

In Bangladesh a number of domestic solar energy systems are in use in houses around the country. The use of solar energy on this scale is highly potential and advantageous as more than $60 \%$ of areas in the country do not have access to main grid electricity. The World Bank is backing a program of making solar energy available to wider population in Bangladesh, as part of the Rural Electrification and Renewable Energy Development Project (REREDP), which subsidizes solar energy systems.

A typical 'solar home system' can power two to eight 'low energy' lights, plus a socket for TV, radio or battery recharging, and a Mobile telephone charging unit, too. Each system consists of a Solar panel mounted on the house roof. Depending on its size, this provides between $40 \mathrm{~W}$ and $135 \mathrm{~W}$ of electricity in full sunlight (the most common being 50W).

Grameen Shakti is the largest organization installing rural based solar home system (SHS) in Bangladesh. Other companies working on similar solar energy based SHS are Rural Services Foundation (RSF), BRAC, CMES (Centre for Mass Education in science), Hilfulfujal and so on. The model of micro finance based SHS is now being copied in other parts of the world as a successful business model.

Rahimafrooz a major supplier of high quality solar batteries and other solar components for the program; Rahimafrooz Renewable Energy Ltd (RRE) has been the pioneer in installing solar powered centralized systems, water pumps for irrigation and pure drinking water, water heaters, street lights, and solar-powered telecom solutions to various organizations. They are working closely with pertinent government organizations in installing solar powered medical refrigerator that provides emergency live saving medicines in the off-grid rural areas.

A company named Digital Technology is doing research and development of solar PV products like solar billboard lighting, mini grid system for irrigation etc.

In Bangladesh, all supplier has involved with mono-crystalline solar and poly-crystalline solar, but no one deal with thin film solar system; due to lack of appropriate solar charge controller for solar home system (SHS). Thin film solar system is cheapest than other solar system, that why I have involved to design and implementation a thin film solar charge controller to do popular as Solar Home System (SHS) in Bangladesh.

\section{Solar Cells}

\subsection{Fundamental of Photovoltaic's}

The direct transformation from the solar radiation energy into electrical energy is possible with the photovoltaic effect by using solar cells. The term photovoltaic is often abbreviated to PV. The radiation energy is transferred by means of the photo effect directly to the electrons in their crystals. With the photovoltaic effect an electrical voltage develops inconsequence of the absorption of the ionizing radiation. Solar cells must be differentiated from photocells whose conductivity changes with irradiation of sunlight. Photocells serve e.g. as exposure cells in cameras since their electrical conductivity can drastically vary with small intensity changes. They produce however no own electrical voltage and need therefore a battery for operation.

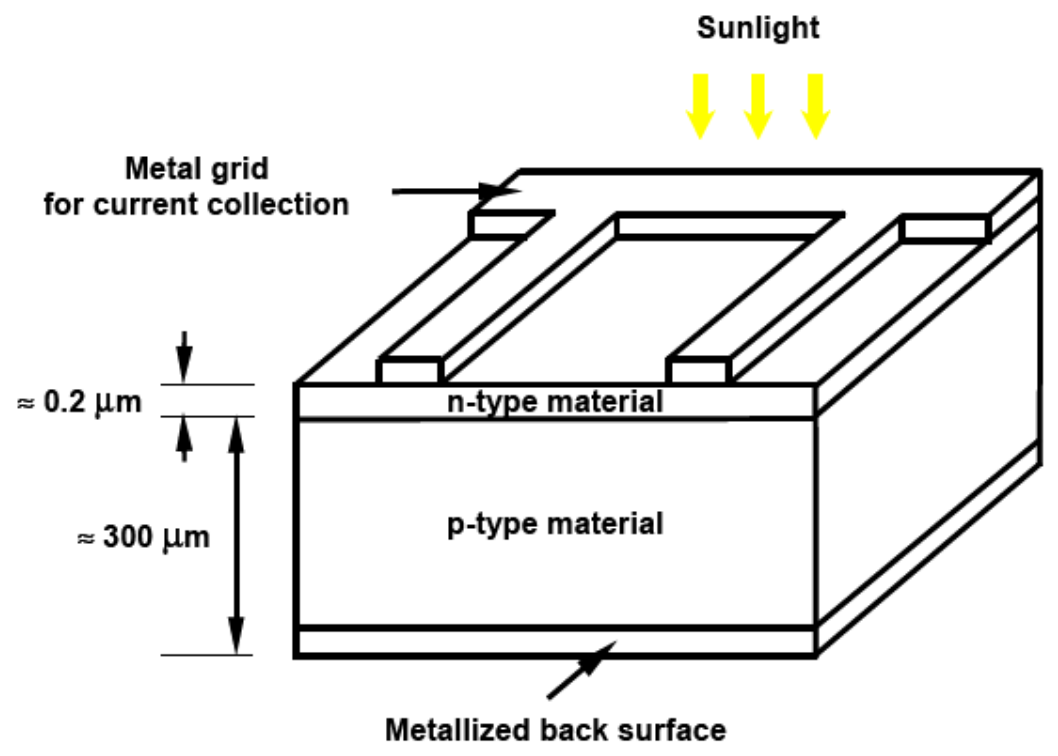

Figure 1. Schematic drawing of a silicon solar cell. 


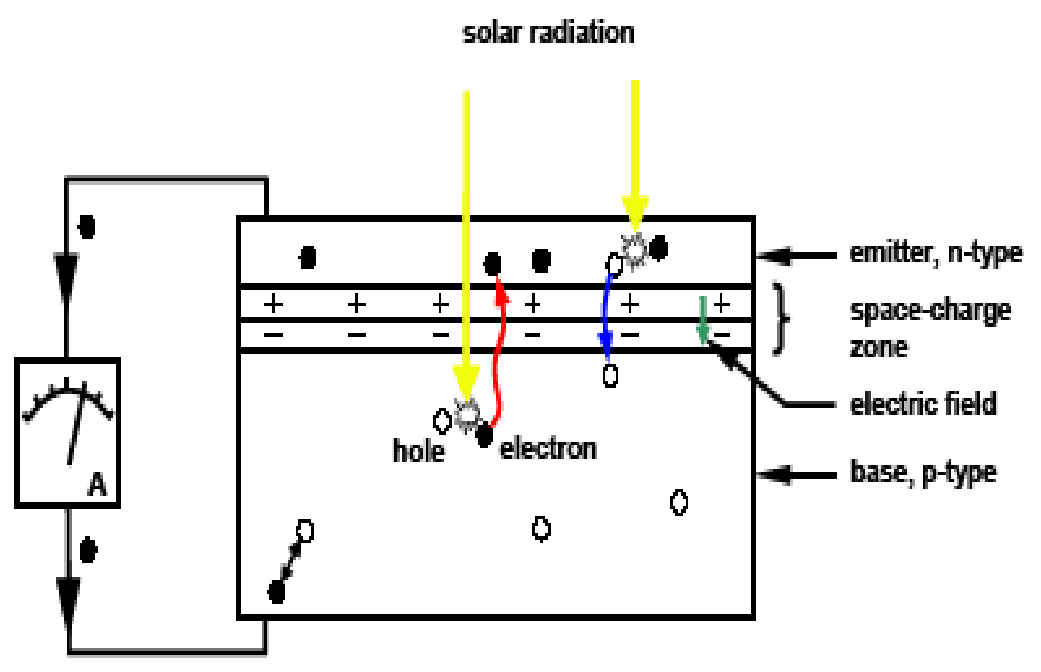

Figure 2. Operating principle of a solar cell (schematic)

\subsection{Physical Processes in Solar Cells}

\subsubsection{Optical absorption}

Light, which falls on a solar cell, can be reflected, absorbed or transmitted. Since silicon has a high refractive index (>3.5), over $30 \%$ of the incident light is reflected. Therefore solar cells are always provided with an antireflection coating. A thin layer titanium dioxide is usual. Thus the reflection losses for the solar spectrum can be reduced to about $10 \%$. More reduction of the reflection losses can be achieved by multi - layer AR layers. A two part layer from titanium dioxide and magnesium fluoride reduces the reflection losses of a remainder up to ca. $3 \%$. Photons (light quanta) interact with materials mainly by excitation of electrons. The main process in the field of energy, in which solar cells are applied, is the photoelectric absorption.

Thereby the photon is completely absorbed by a bound electron. The electron takes the entire energy of the photon and becomes free - electron. However, in semiconductors a photon can be only absorbed if its energy is larger than the band gap. Photons with energies smaller than the band gap pass through the semiconductor and cannot contribute to an energy conversion.

However, photons with much larger energies than the band gap are also lost for the energy conversion since the surplus energy is fast given away as heat to the crystal lattice. During the interaction of the normal solar spectrum with a silicon solar cell, about $60 \%$ of the energy for a transformation is lost because many of the photons possess energies, which are smaller or larger than the band gap.

\subsubsection{Solar cells under incident light}

Figure 2 shows the three main parts of a solar cell schematically: the diffused strong n-doped emitter, the space - charge zone and the $p$ - doped base.

A photon with sufficient large energy falls on the surface of the solar cell penetrates emitters and space - charge zone and is absorbed in the p - base. An electron - hole pair is developed due to the absorption.

Since electrons are in the minority in the $\mathrm{p}$ - base, one calls them minority charge carrier contrary to the holes, which are majority charge carrier here. This electron diffuses in the p-base until it arrives at the boundary of the space charge zone. The existing strong electrical field in the space - charge zone accelerates the electron and brings it to the emitter side.

\subsection{Theoretical Description of the Solar Cell}

According to fundamental theory of photovoltaic, illuminated solar cell creates free charge carriers, which allow current to flow through a connected load. The number of free charge carriers is proportional to the incident radiation intensity. So does also the photo current (Iph), which is internally generated in the solar cell. Therefore an ideal solar cell can be represented by the following simplified equivalent circuit (Fig.3 - 3). It consists of the diode created by the $\mathrm{p}-\mathrm{n}$ junction and a photocurrent source with the magnitude of the current depending on the radiation intensity. An adjustable resistor is connected to the solar cell as a load. The mathematical process of an ideal exposed solar cell leads to the following equation:

$$
\mathrm{I}_{\mathrm{cell}}=\quad \mathrm{I}_{\mathrm{ph}}-\mathrm{I}_{\mathrm{D}}=I_{p h}-I_{0} \cdot\left(e^{\frac{q V}{k T}}-1\right)
$$




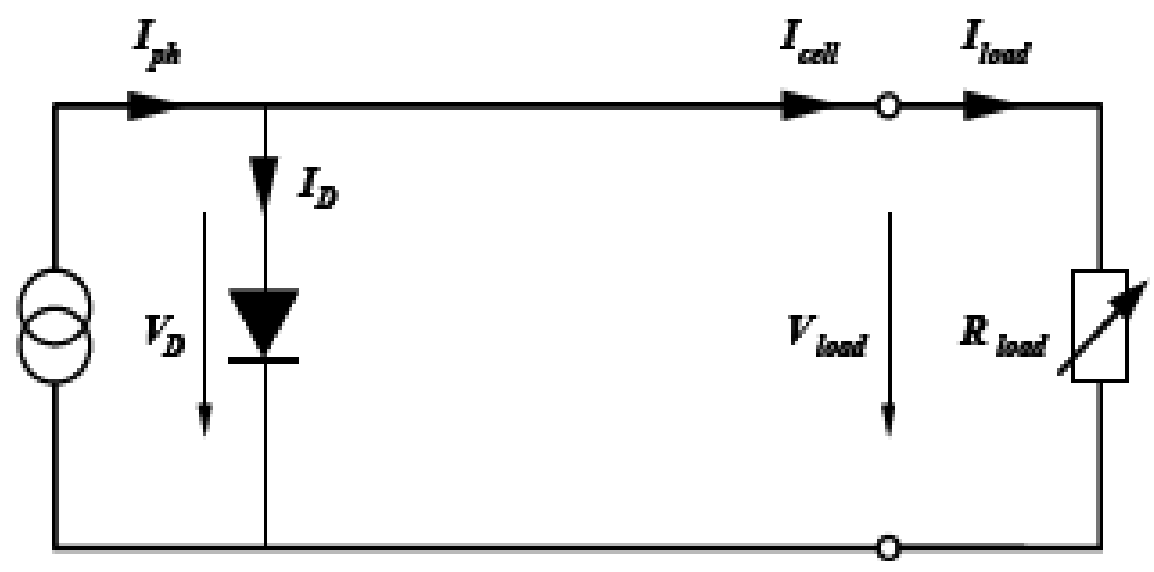

Figure 3. Equivalent circuit diagram of an ideal solar cell connected to load.

In an imaginary experiment, the I - V characteristic curve for a certain incident radiation will now be constructed, point for point figure 4:

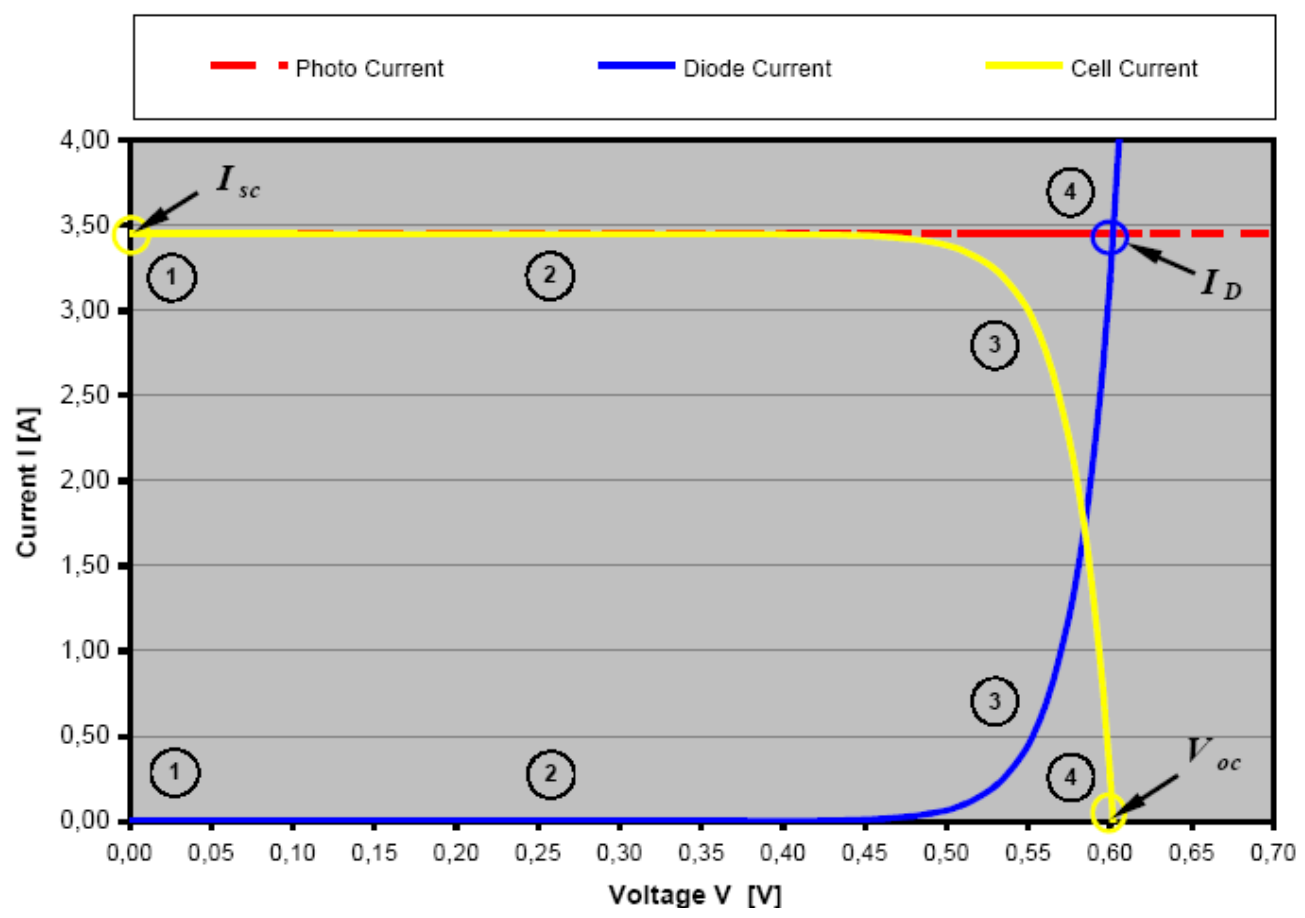

Figure 4. Construction of the solar cell curve from the diode curve.

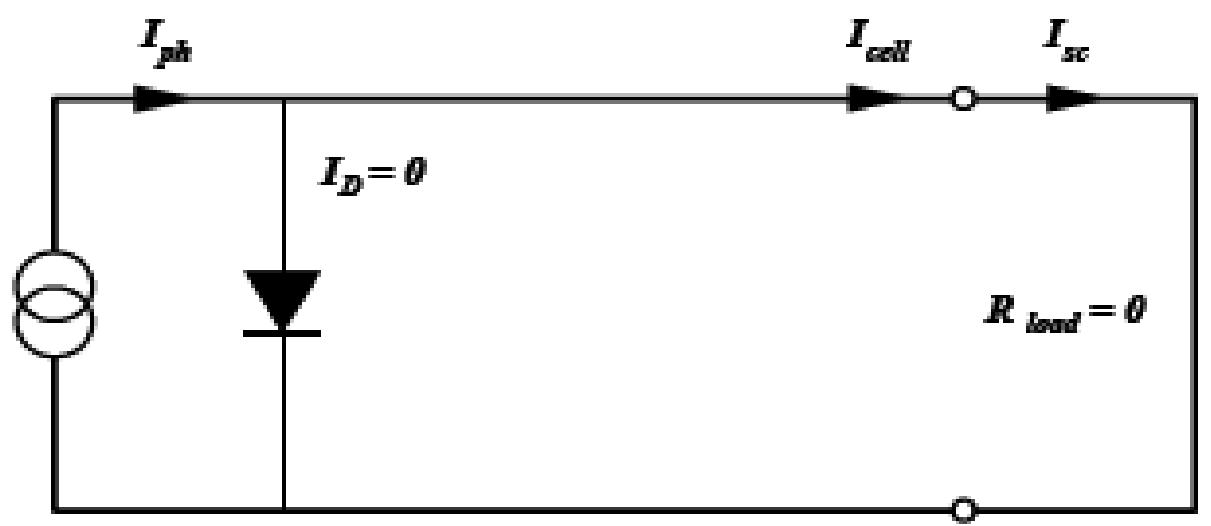

Figure 5. Equivalent circuit diagram of the solar cell - short - circuit current. 
When the terminals are short - circuited $(\mathrm{R}$ load $=0)$ (Figure 4), the output voltage and thus also the voltage across the diode is zero. Since $V=0$, no current ID flows (point 1 in Figure 4) therefore the entire photocurrent I ph generated from the radiation flows to the output. Thus the cell current has its maximum at this point with the value I cell and refers to the so - called short - circuit current I sc.

$\mathrm{I} s \mathrm{sc}=\mathrm{I}$ cell $=\mathrm{I} \mathrm{ph}$, the current remains constant. Up to a certain voltage value the current flowing through the internal diode remains negligible, thus the output current continues corresponding to the photo current (point 2 in Figure 4).Until the diode voltage threshold is exceeded after the load resistance is further increased a rapidly increasing proportion of the photo current flows through the diode. This current leads to power loss in the internal diode corresponding to an area between the photocurrent curve and the cell current curve. Since the sum of the load current and the diode current must be equal to the constant photocurrent, the output current decreases by exactly this amount (point 3 in Figure 4).

The output current is then zero (I cell $=0$ ) and thus the entire photocurrent flows through the internal diode (point 4 in Figure 7). The open - circuit voltage Voc can be therefore derived again -

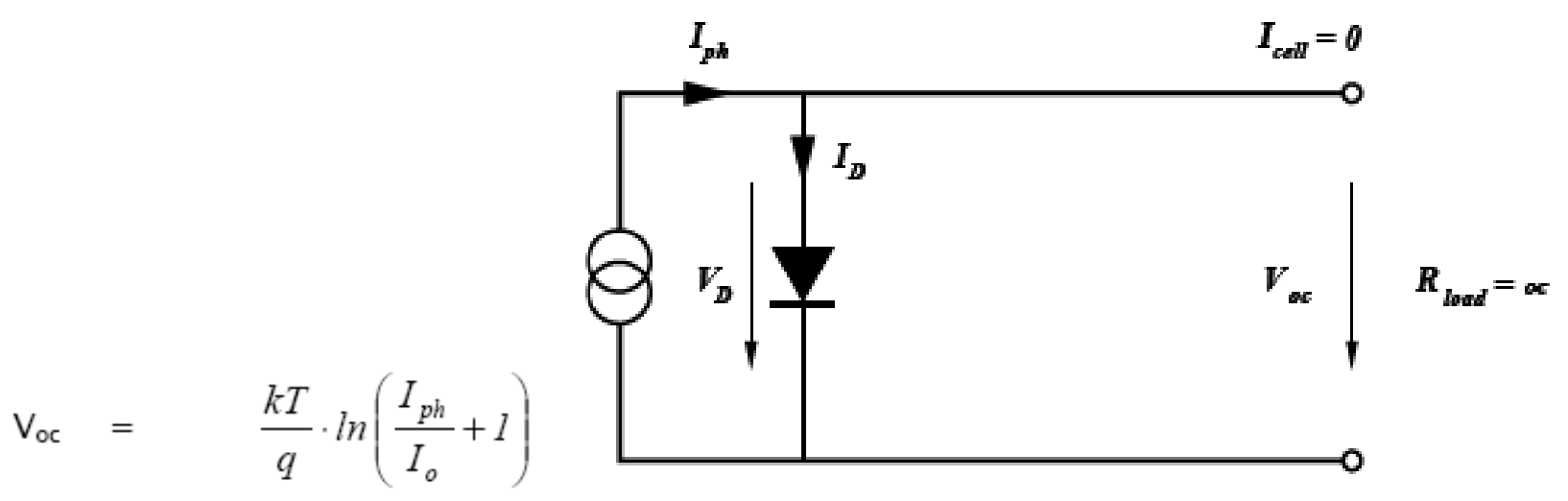

Figure 6. Equivalent circuit diagram of the solar cell - open - circuit voltage.

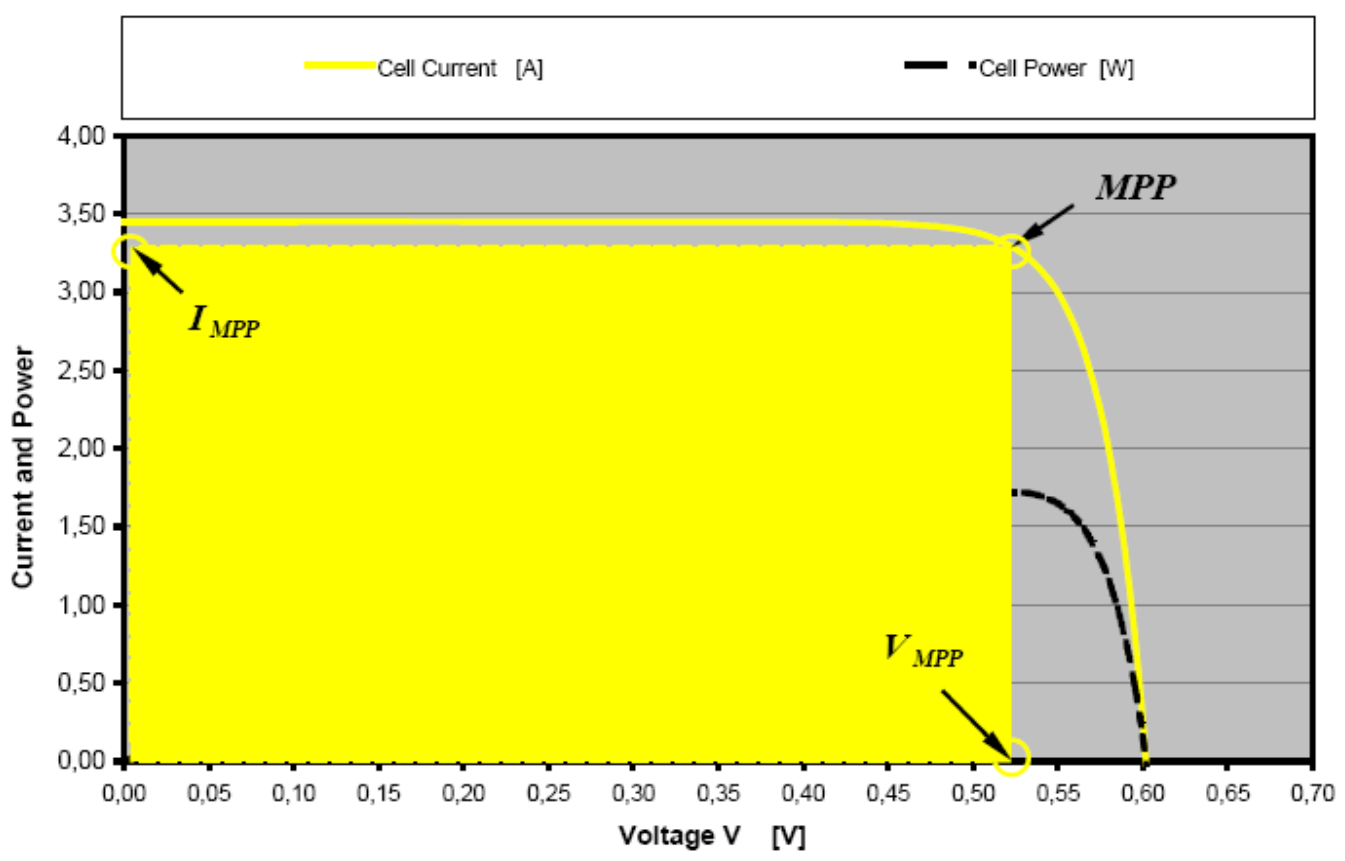

34Figure 7. Power curve and maximum power point (MPP). 
In addition, typical value of the open - circuit voltage is located ca. $0.5-0.6 \mathrm{~V}$ for crystalline cells and $0.6-0.9 \mathrm{~V}$ for amorphous cells. From this experiment it becomes obvious that the characteristic curve for a solar generator is equivalent to an "inverted" diode characteristic curve, which is shifted upward by an offset equal to the photocurrent (= short - circuit current). Since electric power is the product of current and voltage, therefore a curve of the power delivered by a solar cell can be obtained for a given radiation level (Figure 7).

Although the current has its maximum at the short circuit point, the voltage is zero and thus the power is also zero. The situation for current and voltage is reversed at the open - circuit point, so again the power here is zero. In between, there is one particular combination of current and voltage, for which the power reaches a maximum (graphically indicated with a rectangle area in Figure 6. The so - called maximum power point (MPP) represents the working point, at which the solar cell can deliver maximum power for a given radiation intensity. It is situated near the bend of the I - V characteristic curve. The corresponding values of VMMP and IMMP can be estimated from Voc and I sc as follows -

$$
\mathrm{VMMP} \approx(0.75-0.9) \mathrm{Voc}
$$

$\mathrm{IMMP} \approx$ $(0.85-0.95)$ I sc

In addition, the quantity

$$
\mathrm{FF}=\frac{\left(V_{M P P} \cdot I_{M P P}\right)}{\left(V_{o c} \cdot I_{s c}\right)}
$$

is called Fill Factor represents the measure for the quality of the solar cell. It indicates how far the I - V characteristic curve approximates to a rectangle. Normally the value for crystalline solar cells is about $0.7-0.8$. The maximum output power of the cell is then $\mathrm{PMPP}=\mathrm{VMPP} * \mathrm{IMPP}=\mathrm{Voc} * \mathrm{I} \mathrm{sc} * \mathrm{FF}$

Thus the efficiency of the solar cell, which refers to the ratio of the output electrical energy to the input solar radiation (Pin), is defined by the following relation.

$$
\eta=\frac{V_{o c} \cdot I_{s c} \cdot F F}{P_{i n}}
$$

Until now the highest obtained efficiencies of the silicon solar cells with irradiation of a solar spectrum AM 1.5 are approx. $24 \%$. The efficiencies of the silicon solar cells from the line production for terrestrial applications are situated between 10 and $14 \%$. The theoretical efficiencies of the silicon solar cell is however ca. $26-27 \%$.

\subsection{Conditions with Real Solar Cells}

\subsubsection{Influence of series- and parallel resistance}

With regard to the behavior of a real solar cell, two parasitic resistances inside the cell, namely a series - (Rs) and parallel resistance ( $\mathrm{Rp})$, are taken into consideration for more exact description as indicated in the equivalent circuit diagram in Figure 7.

The series resistance arises from the bulk resistance of the silicon wafer, the resistance of the metallic contacts of the front - and back surface and further circuit resistances from connections and terminals. The parallel resistance is mainly caused by leakage currents due to $\mathrm{p}-\mathrm{n}$ junction non idealities and impurities near the junction, which cause partial shorting of the junction, particularly near the cell edges.

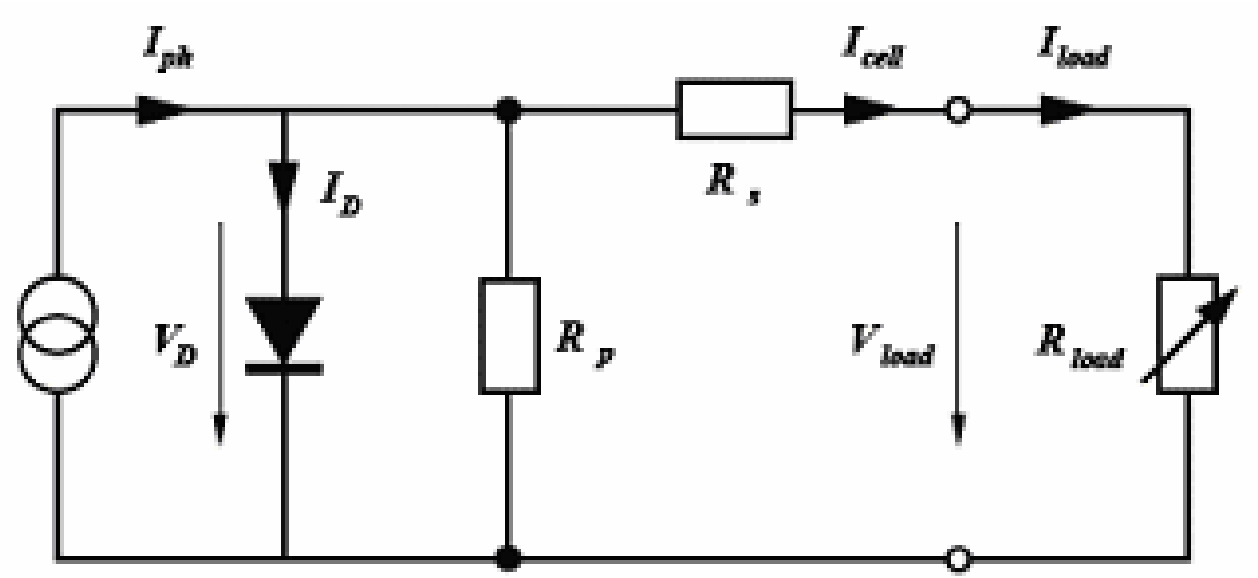

Figure 8. Equivalent circuit diagram of a real solar cell 


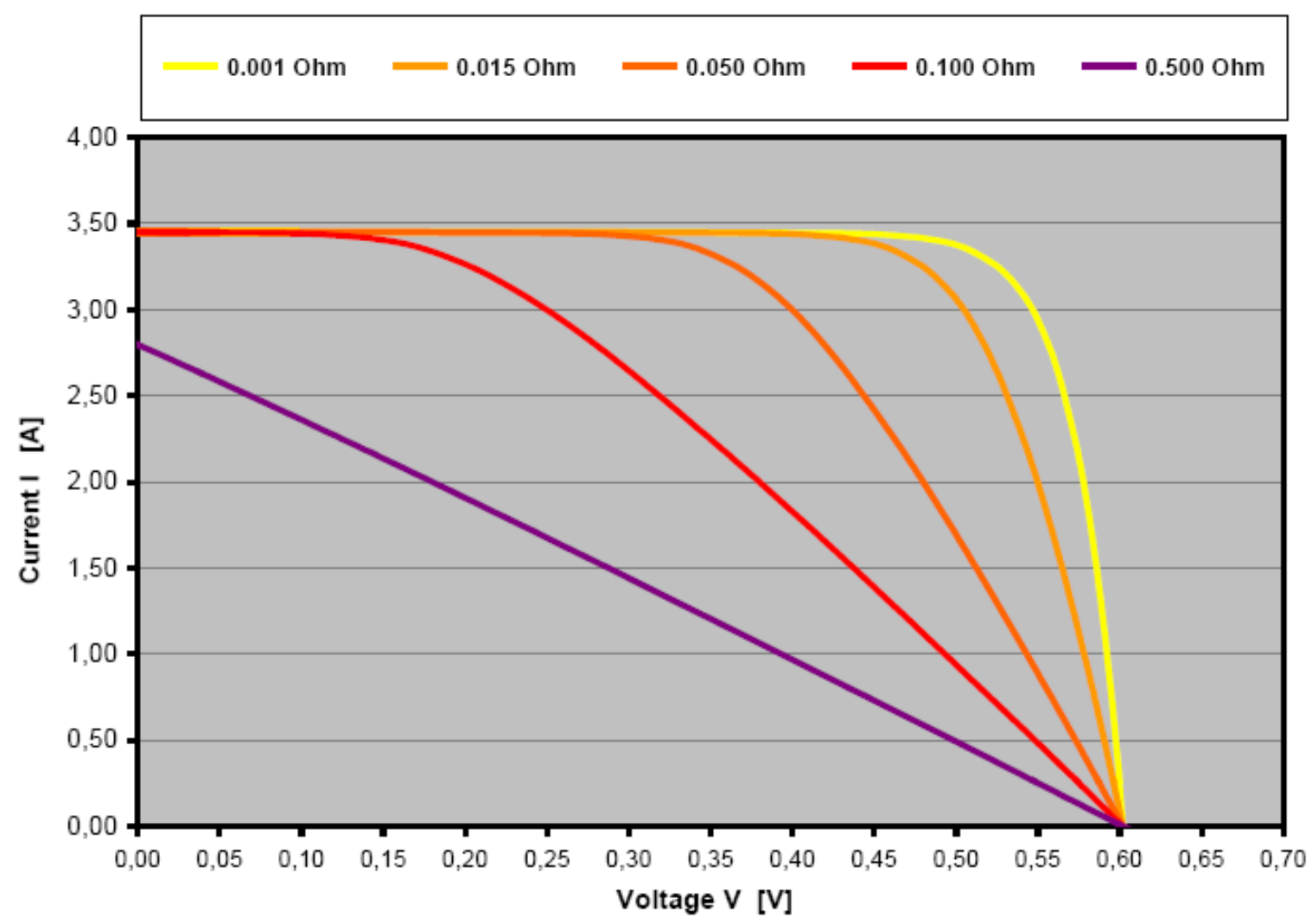

Figure 9. I - V curve for different parallel resistances.

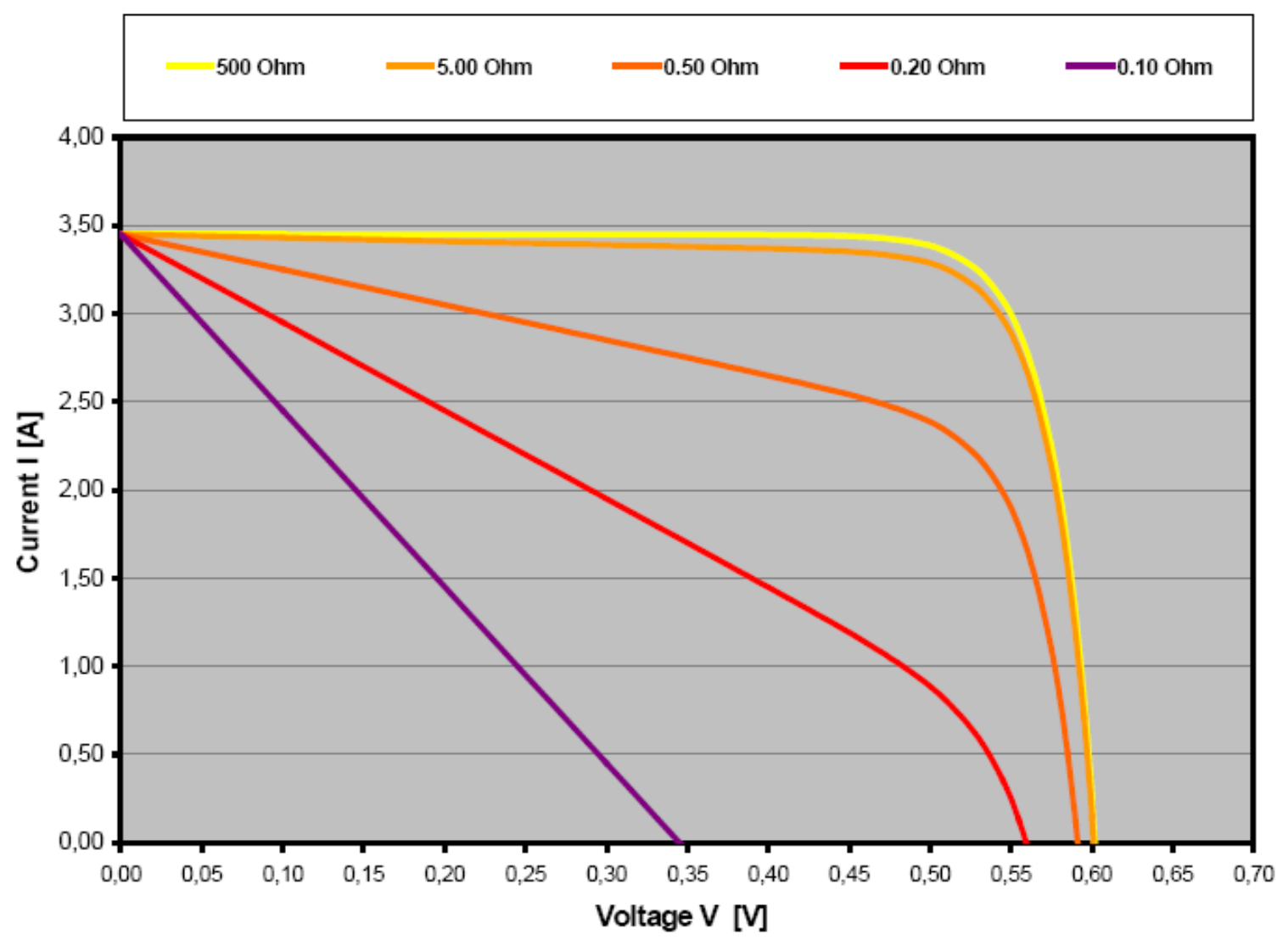

Figure 10. I - V curve for different series resistances. 


\subsubsection{Sources of losses in solar cells}

- A part of the incident light is reflected by metal grid at the front. Additional reflection losses arise during radiation transition from the air into the semiconductor material due to different indexes of refraction. These losses are reduced by coating the surface with antireflection layer. Another possibility is a structuring the cell surface.

- The solar radiation is characterized by a wide spectral distribution, i.e. it contains photons with extreme different energies. Photons with small energy than the band gap are not absorbed and thus are unused. Since the energies are not sufficient to ionize electrons, electron - hole pairs will not be produced. In case of photons with larger energy than the band gap, only amount of energy equal to the band gap is useful, regardless of how large the photon energy is. The excess energy is simply dissipated as heat into the crystal lattice.

- Since the photocurrent is directly proportional to the number of photons absorbed per unit of time, the photocurrent increases with decreasing band gap. However, the band gap determines also the upper limit of the diffusion voltage in the $\mathrm{p}-\mathrm{n}$ junction. A small band gap leads therefore to a small open - circuit voltage. Since the electrical power is defined by the product of current and voltage, a very small band gaps result in small output power and thus low efficiencies. In case of large band gaps, the open - circuit voltage will be high. However, only small part of the solar spectrum will be absorbed. As a result, the photocurrent achieves here only small values. Again, the product of current and voltage stays small.
- The dark current is larger than the theoretical value. This reduces the open - circuit voltage.

- Not all charge carriers produced are collected, some recombine. Charge carriers recombine preferably at imperfections, i.e. lattice defects of crystal or impurities. Therefore, source material must have a high crystallographic quality and provide most purity. Likewise, the surface of the semiconductor material is a place, in which the crystal structure is very strongly disturbed, and forms a zone of increasing recombination.

- The Fill factor is always smaller than one (theoretical max. value ca. 0.85 ).

- Series - and parallel resistance result in reduction of the Fill factor.

\subsection{From Single Cells to PV Arrays}

Solar cells are rarely used individually. Rather, cells with similar characteristics are connected and encapsulated to form modules in order to obtain higher power values. These modules are then in turn combined to construct arrays. PV arrays for a diversity of applications can be constructed according to this principle in the power range from $\mu \mathrm{W}$ to MW.

\subsubsection{Parallel connection}

If higher current is required in a system, solar cells are connected in parallel as illustrated in figure - $3-10$.

Regarding a parallel - connected configuration the voltage across each cell is equal whereas the total current is the sum of all the individual cell currents. Accordingly, the current-voltage characteristic curve of the complete configuration is obtained, as shown in figure 11, by adding the single cell current values corresponding to each voltage value point for point.

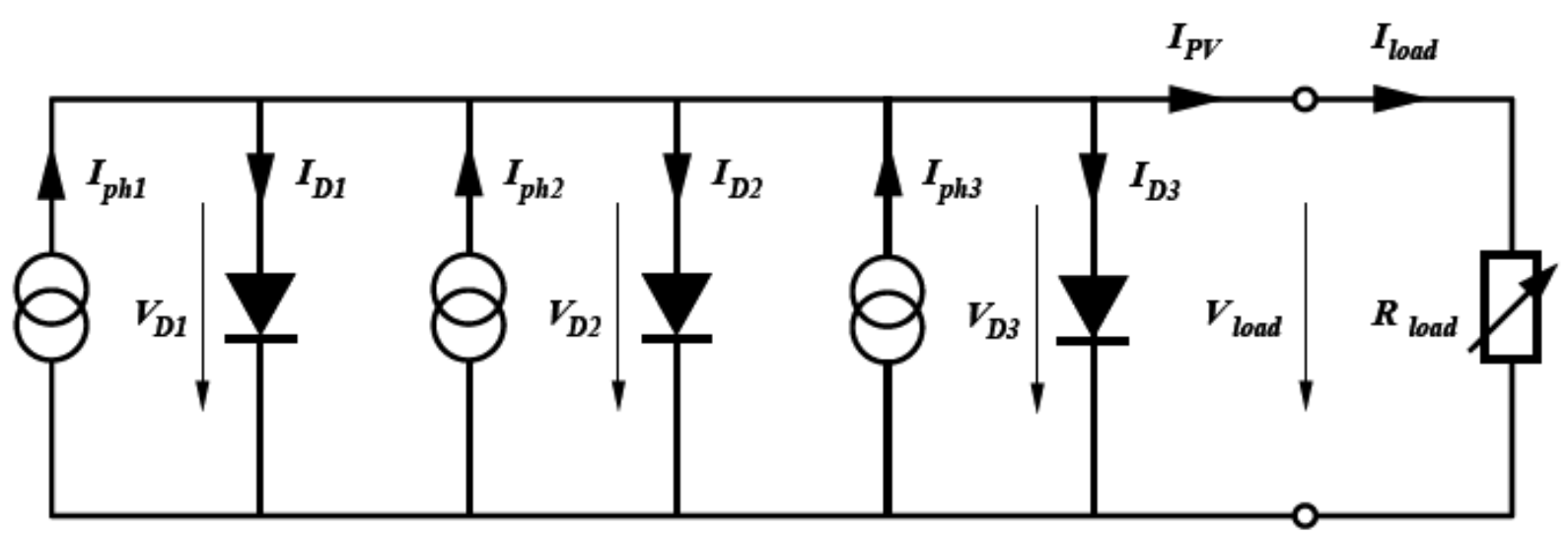

Figure 11. Parallel connection of solar cells. 


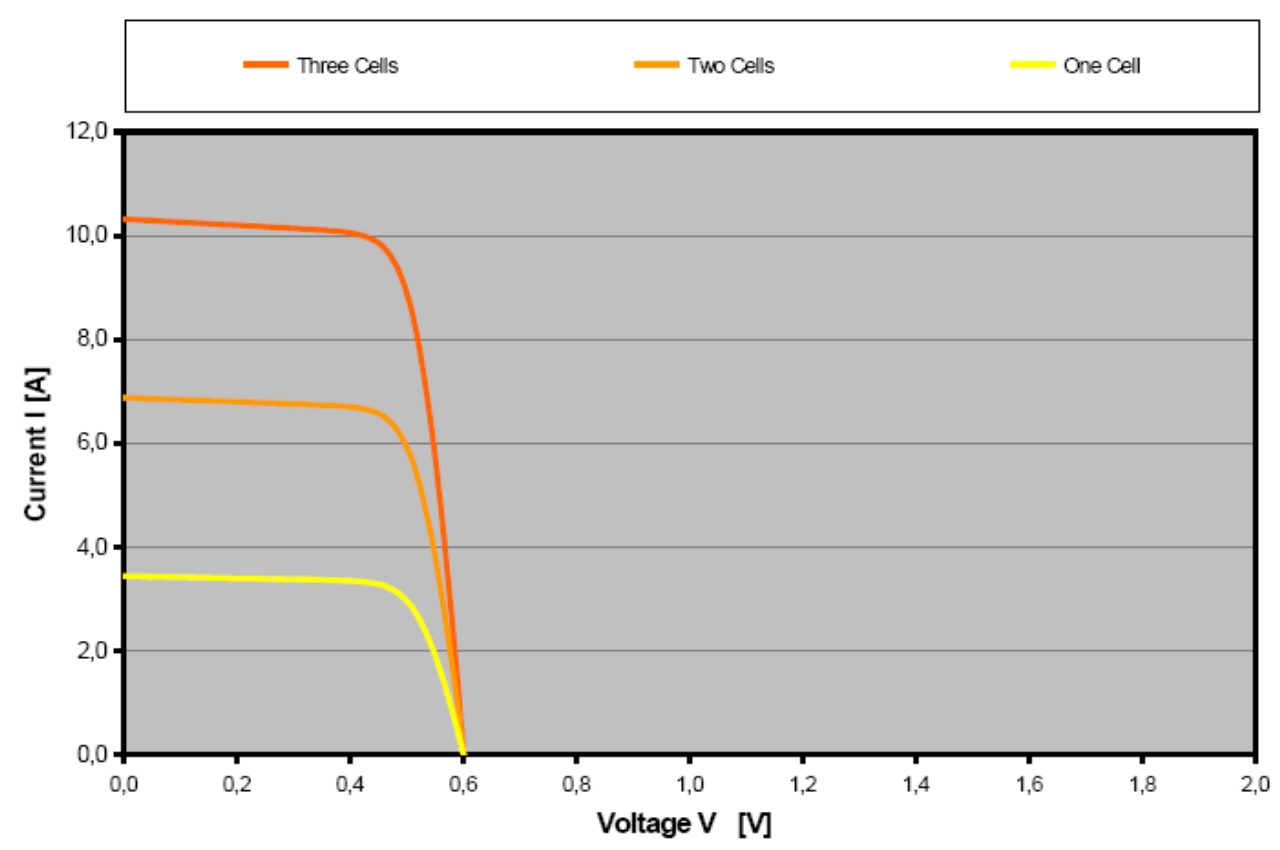

Figure 12. I - V characteristic curve for parallel connection.

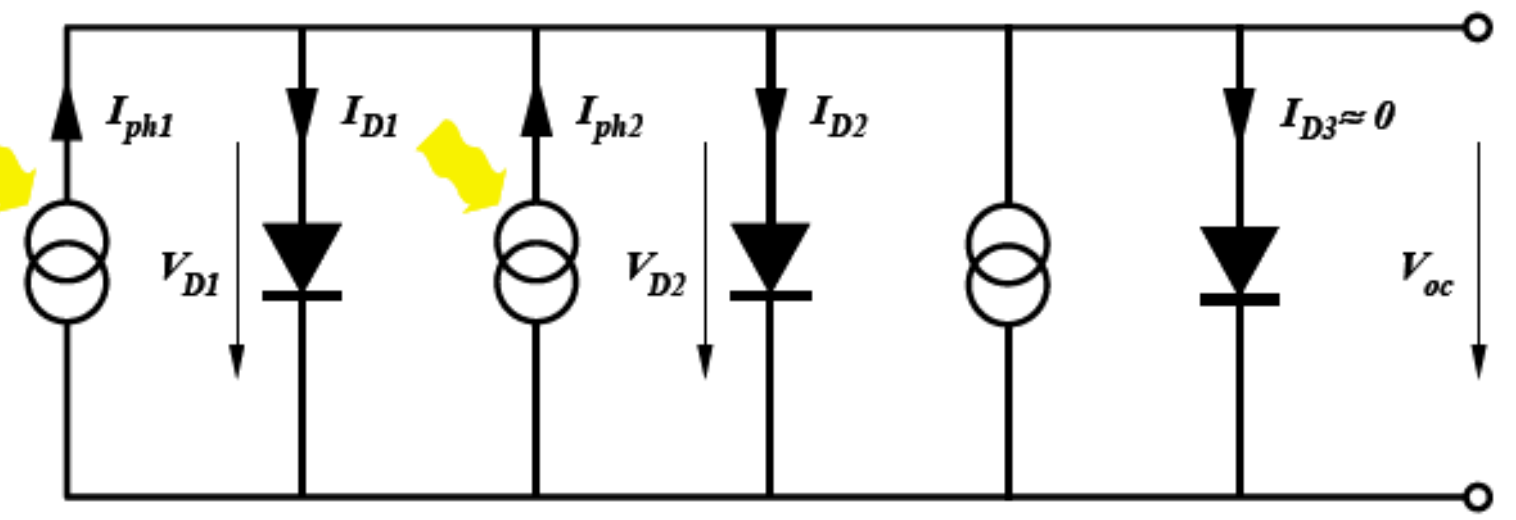

Figure 13. Partial shading in case of parallel connection.

The question of the system performance arises when part of a module is shaded. As indicated in Figure 2 - 11 three identical cells are connected in parallel and one cell is completely shaded, which then stops generating its photocurrent. The worst case takes place with open - circuit condition, i.e. if there is no external load. Since the shaded cell is cooler than the other two cells, the breakdown voltage of its diode is higher according to their I - V characteristic curves. Whereas the voltage across all three cells is identical, the diode current of the shaded cell is therefore extremely small.

Pure parallel connection in order to construct a module is usually not suitable for common application because high current requires big cross section of conductor. Besides, low voltage causes high relative losses. For these reasons a series connection is more attractive.

\subsubsection{Series connection}

In a series connection, as illustrated in Figure 14, the same current flows through each cell whereas the total voltage is the sum of the voltage across each cell. The I - V characteristic curve of the complete configuration, as shown in Figure - 13, is obtained by adding the single cell voltage value corresponding to each current value point for point.

The following characteristic curves result for a given radiation intensity, which is equal for three of solar cells. Series connection of the solar cells causes an undesired effect when a PV module is partly shaded. In contrast with parallel connection, the worst case occurs in case of short circuit connection. 


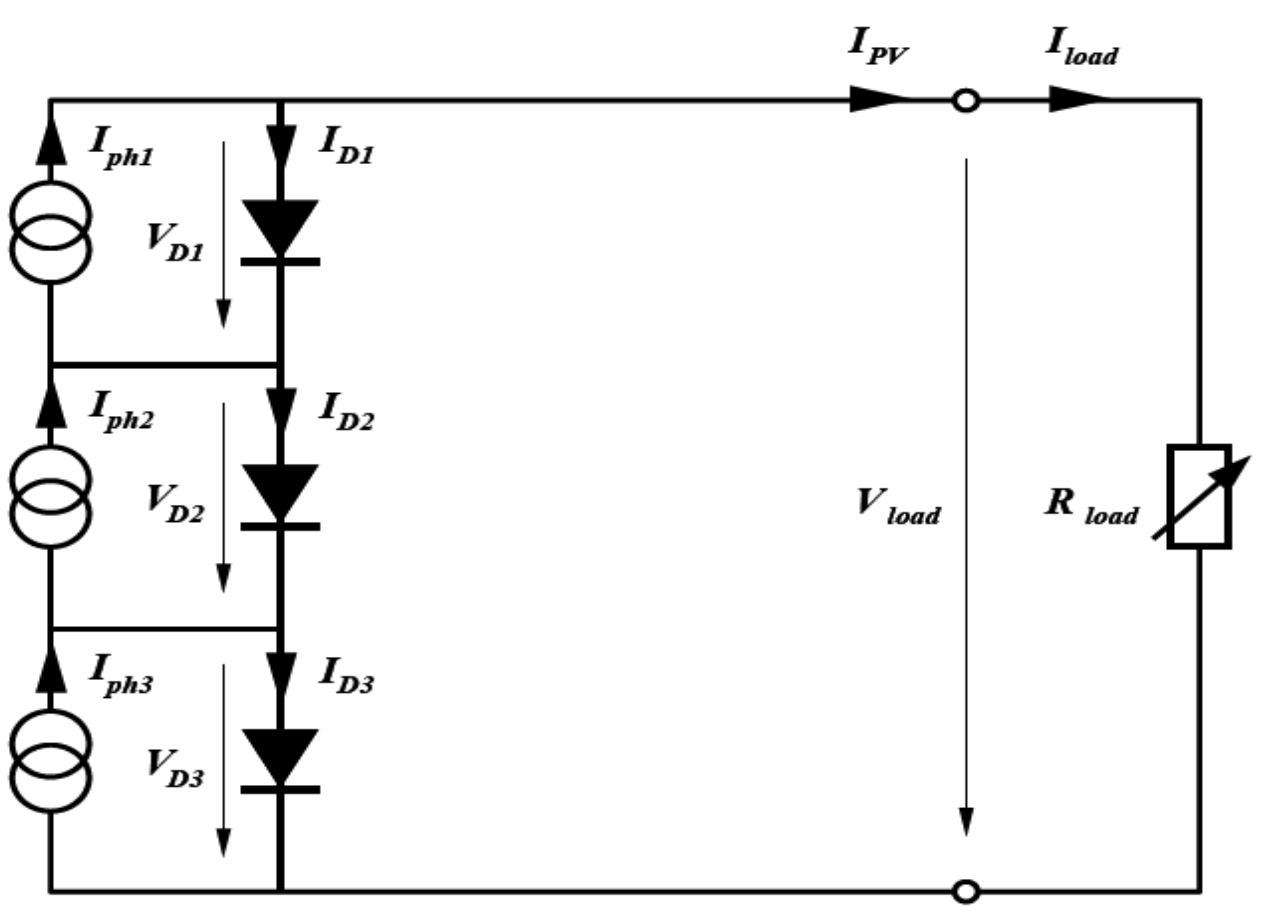

Figure 14. Series connection of solar cells.

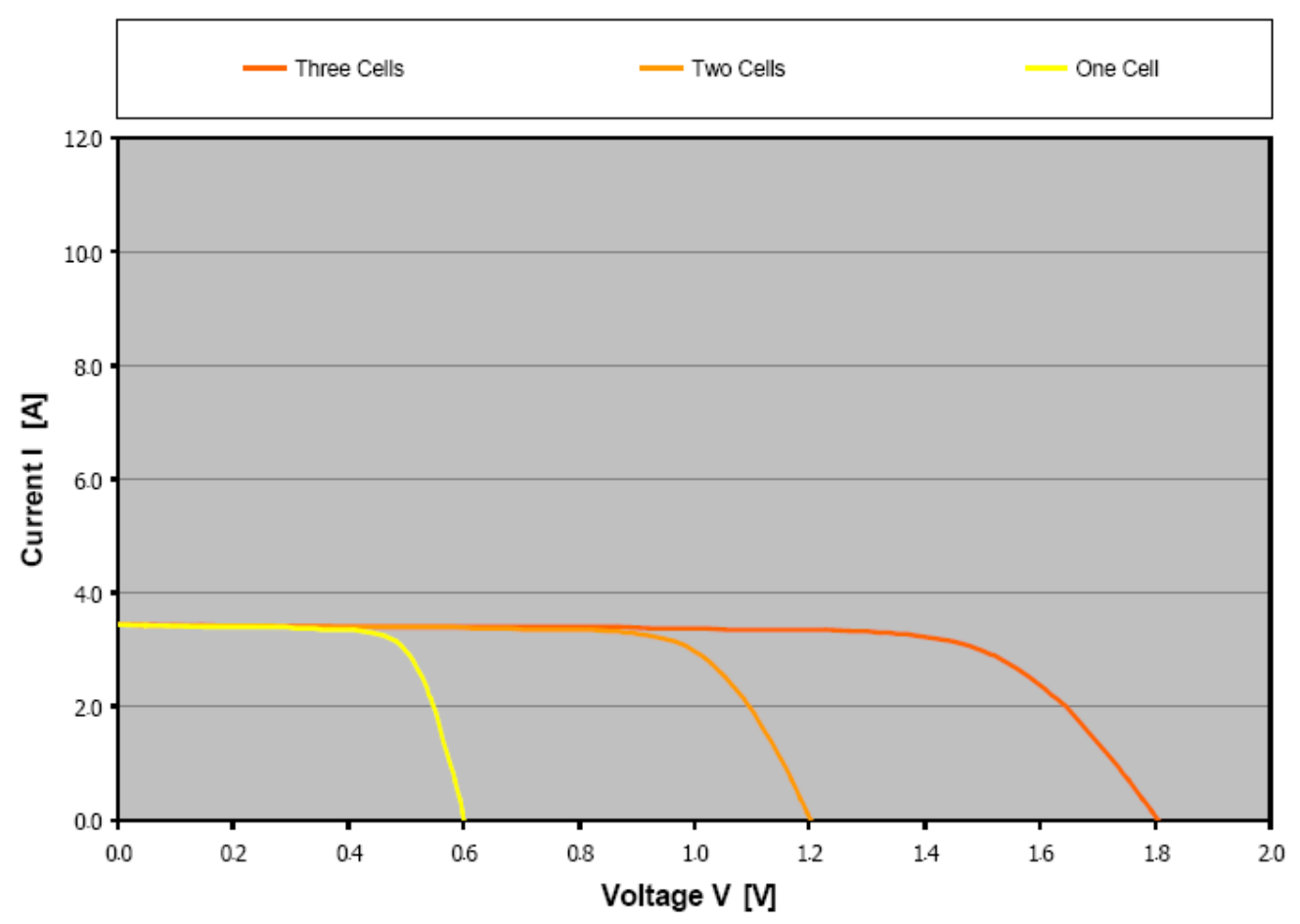

Figure 15. I - V characteristic curve for series connection.

In case of complete shading as shown in Figure 16 the shaded cell generates no current and acts as an open - circuit and therefore no current flows in the circuit. Its diode tends to be reverse biased by the voltage generated from other two cells. However, there is no power dissipation to the shaded cell unless the breakdown voltage of its diode is exceeded.

Due to the fact that there is no current flowing in the circuit, the output power in this case is also zero. One solution to this problem is to connect bypass diode anti parallel to the cells(Figure 15) so that larger voltage differences cannot arise in the reverse - current direction of the solar cells. Under normal conditions such as with no shading each bypass diode is reverse biased and each cell generates power.

As shown in Figure 16, when the third cell is shaded, its bypass diode is forward biased and conducts the circuit 
current. Regarding the I - V characteristic curve of the PV array incase of shading by assuming that the load is adjusted from infinity (open - circuit) to zero(short - circuit), the result is shown in Figure 17. Under open - circuit condition no current flows through the circuit and there is no voltage across the third cell. When the load is smaller than infinity, the load voltage is smaller than open - circuit voltage and the voltage across the third cell increases from zero, its bypass diode is therefore forwards based and will conduct the circuit current as soon as its threshold voltage is reached. Afterwards, the characteristic corresponds to the curve of two cells connected in series.

$$
I_{P V}=0
$$

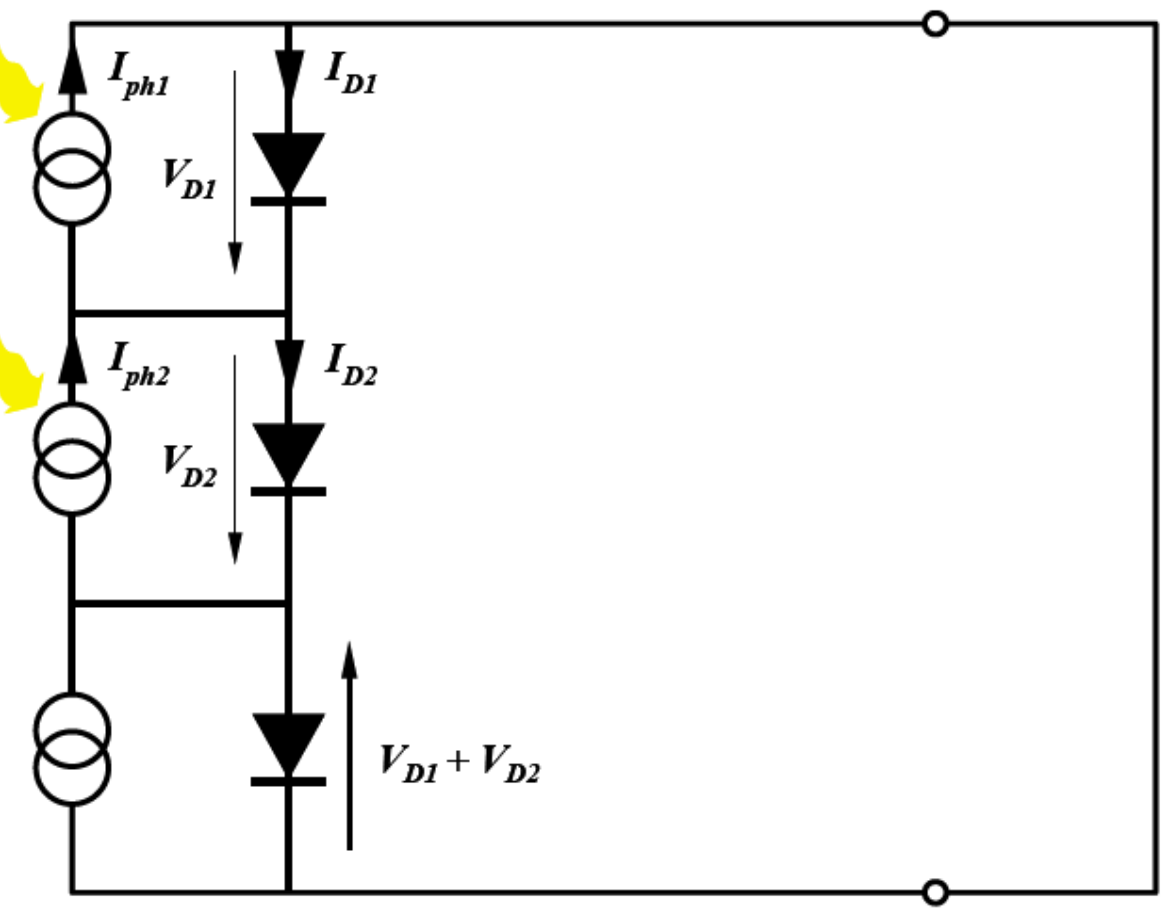

Figure 16. Series connection - one cell is completely shaded.

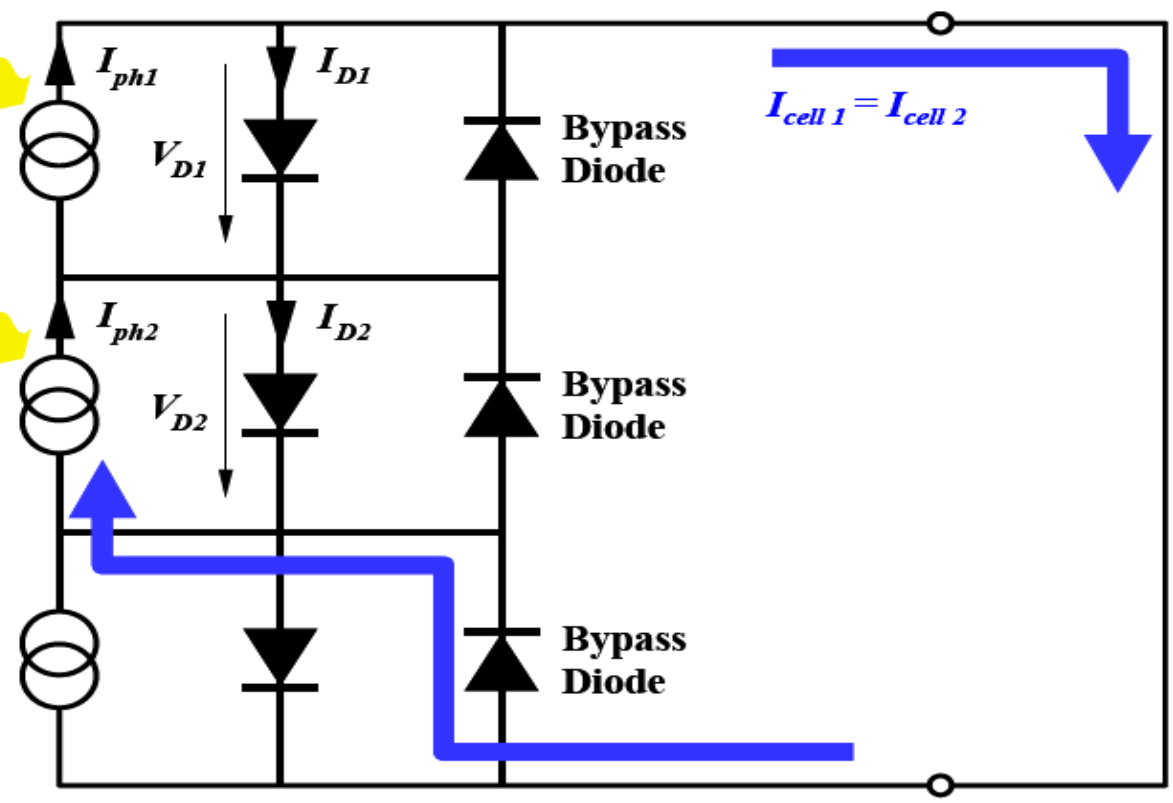

Figure 17. Series connection with bypass diodes - one cell is completely shaded. 


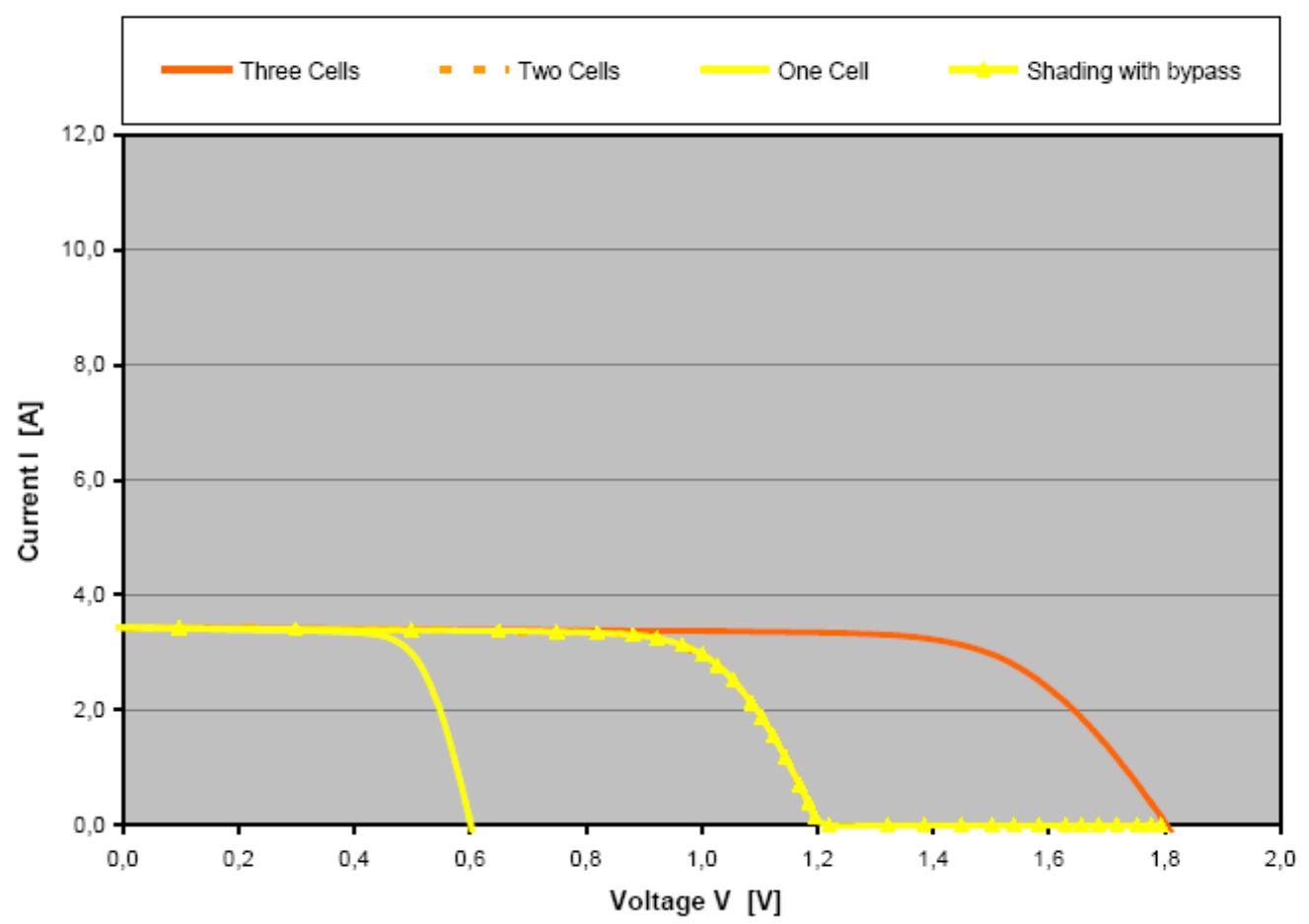

Figure 18. I - V characteristic curve for series connection - one cell is completely shaded.

In case that the third cell is partly shaded (Fig 2 - 16, it can produce approx. $20 \%$ of the photocurrent produced by the other two cells. Regarding series connection, although the other two cells can produce their $100 \%$ photocurrents, the amount of current flowing in the circuit can only equal the amount of the current produced by the third cell.

The rest of the current produced by the first cell will flow into its own diode (this is also applied to the second cell). In addition, the diode of the third cell is reverse biased by the voltage generated by the other two cells. Therefore, power dissipation to the third cell arises

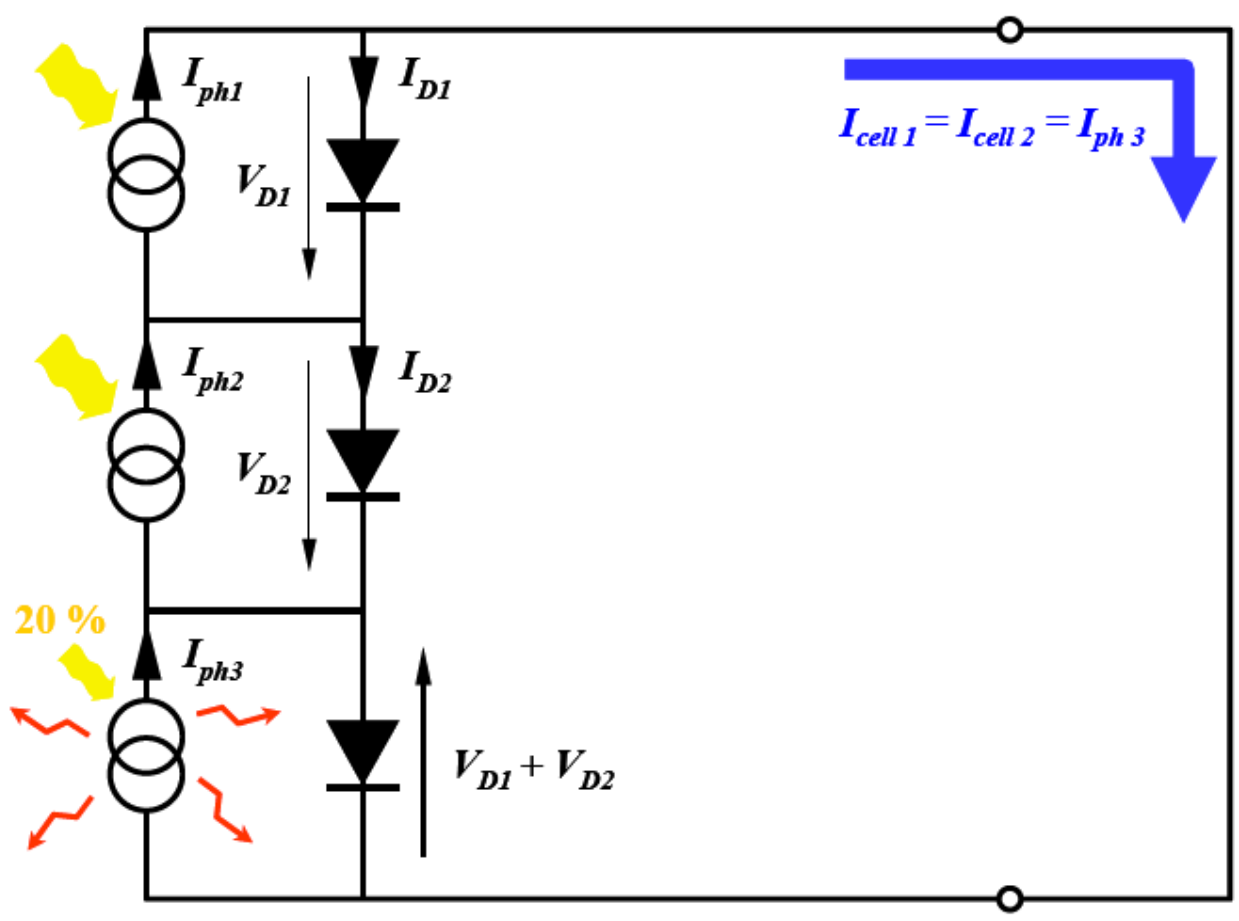

Figure 19. Series connection - one cell is partly shaded. 


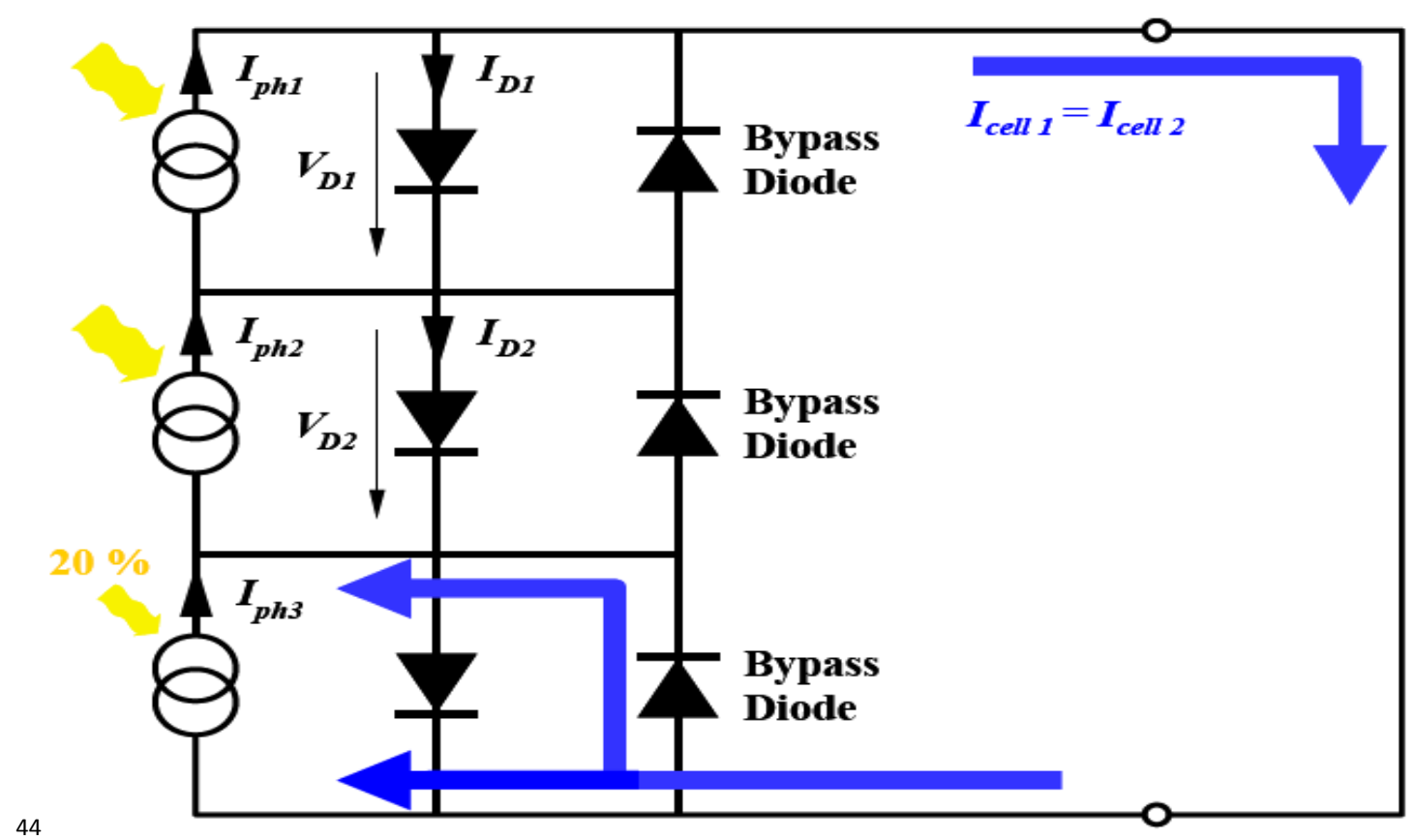

Figure 20. Series connection with bypass diodes - one cell is partly shaded.

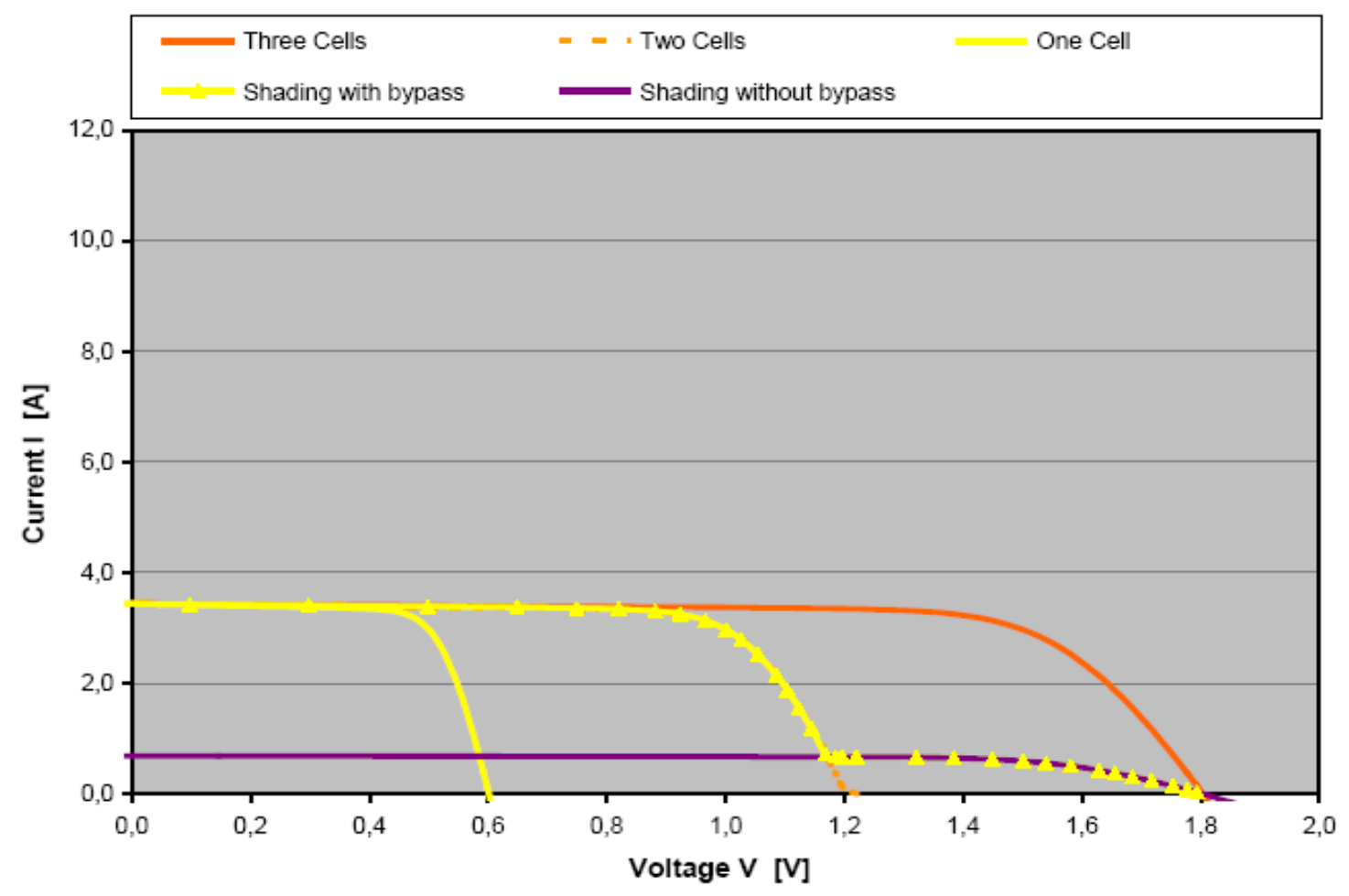

Figure 21. I - V characteristic curve for series connection - one cell is partly shaded.

Such power dissipation refers to the so - called hot spot: an intolerable effect, which leads to breakdown in the cell $p$ - $\mathrm{n}$ junction and in turn to destructions, i.e. cell or glass cracking or melting of solder. However, this can also happen in case of mismatched cells within the module due to manufacturing differences, degradation (cracked) or even unequal illuminated cells, which then result in different outputs. By means of the bypass diodes the problems of mismatched cells and hot spots can be avoided. After the bypass of the third cell conducts, the current flowing through it is equal to the different amount between the circuit current and the current produced by the third cell. The I - V characteristic curve of this case is indicated in Figure 21.

However one bypass diode per cell is generally too expensive. In practice, according to reasons of permissible power loss, it is sufficient to provide one diode for every 10 
to 15 cells, i.e. for a normal 36 - cell module three diodes are needed. In addition, these connections are included in the connection box by the manufacturer. It should be noted that the bypass diodes do not cause any losses while current does not flow through them in normal operation. In addition to protecting the shaded module, the bypass diode also allows current to flow through the PV array when it is partly shaded even if at a reduced voltage and power.

\section{Thin Film Solar Cells}

\author{
Three Photovoltaic Technologies: \\ - Mono crystalline, \\ - Polycrystalline and \\ - Thin Film.
}

Mono crystalline (also called Single Crystal) vs. Polycrystalline, Mono crystalline and Polycrystalline represent the "traditional" technologies for solar panels. They can be grouped into the category "crystalline silicon".

3.1. Mono crystalline, or Single Crystal, is the original PV technology invented in 1955, and never known to wear out. Polycrystalline entered the market in 1981. It is similar in performance and reliability. Single crystal modules are composed of cells cut from a piece of continuous crystal. The material forms a cylinder which is sliced into thin circular wafers. To minimize waste, the cells may be fully round or they may be trimmed into other shapes, retaining more or less of the original circle. Because each cell is cut from a single crystal, it has a uniform color which is dark blue.

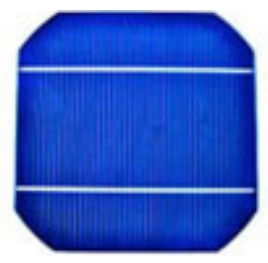

3.2. Polycrystalline cellsare made from similar silicon material except that instead of being grown into a single crystal, they are melted and poured into a mold. This forms a square block that can be cut into square wafers with less waste of space or material than round single-crystal wafers. As the material cools, it crystallizes in an imperfect manner, forming random crystal boundaries. The efficiency of energy conversion is slightly lower. This merely means that the size of the finished module is slightly greater per watt than most single crystal modules. The cells look different from single crystal cells. The surface has a jumbled look with many variations of blue color. In fact, they are quite beautiful like sheets of gemstone.

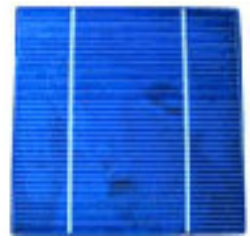

In addition to the above processes, some companies have developed alternatives such as ribbon growth and growth of crystalline film on glass. Most crystalline silicon technologies yield similar results, with high durability. Twenty-five-year warranties are common for crystalline silicon modules. Single crystal tends to be slightly smaller in size per watt of power output, and slightly more expensive than polycrystalline.

The construction of finished modules from crystalline silicon cells is generally the same, regardless of the technique of crystal growth. The most common construction is by laminating the cells between a tempered glass front and a plastic backing, using a clear adhesive similar to that used in automotive safety glass. It is then framed with aluminum.

The silicon used to produce crystalline modules is derived from sand. It is the second most common element on earth, so why is it so expensive? The answer is that, in order to produce the photovoltaic effect, it must be purified to an extremely high degree. Such pure "semiconductor grade" silicon is very expensive to produce. It is also in high demand in the electronics industry because it is the base material for computer chips and other devices. Crystalline solar cells are about the thickness of a human fingernail. They use a relatively large amount of silicon.

\subsection{Thin Film Solar Cell}

The solar panel is an enduring icon of the quest for renewable energy. We'll see the black-paned rectangles on the rooftops of houses or assembled into arrays across fields and prairies. But the panel as we have come to know it -- 5.5 feet by 2.75 feet by 2 inches $(1.7 \mathrm{~m}$ by $0.8 \mathrm{~m}$ by $5 \mathrm{~cm}$ ) -- may be history. That's because a new type of technology stands ready to take its rightful place next to traditional silicon wafer-based panels as an efficient, cost-effective way to convert sunlight into electricity. The technology is the thin-film photovoltaic (PV) cell.

Thin Film Technologies- Imagine if a PV cell was made with a microscopically thin deposit of silicon, instead of a thick wafer. It would use very little of the precious material. Now, imagine if it was deposited on a sheet of metal or glass, without the wasteful work of slicing wafers with a saw. Imagine the individual cells deposited next to each other, instead of being mechanically assembled. That is the idea behind thin film technology. (It is also called amorphous, meaning "not crystalline".) The active material may be silicon, or it may be a more exotic material such as cadmium telluride. 


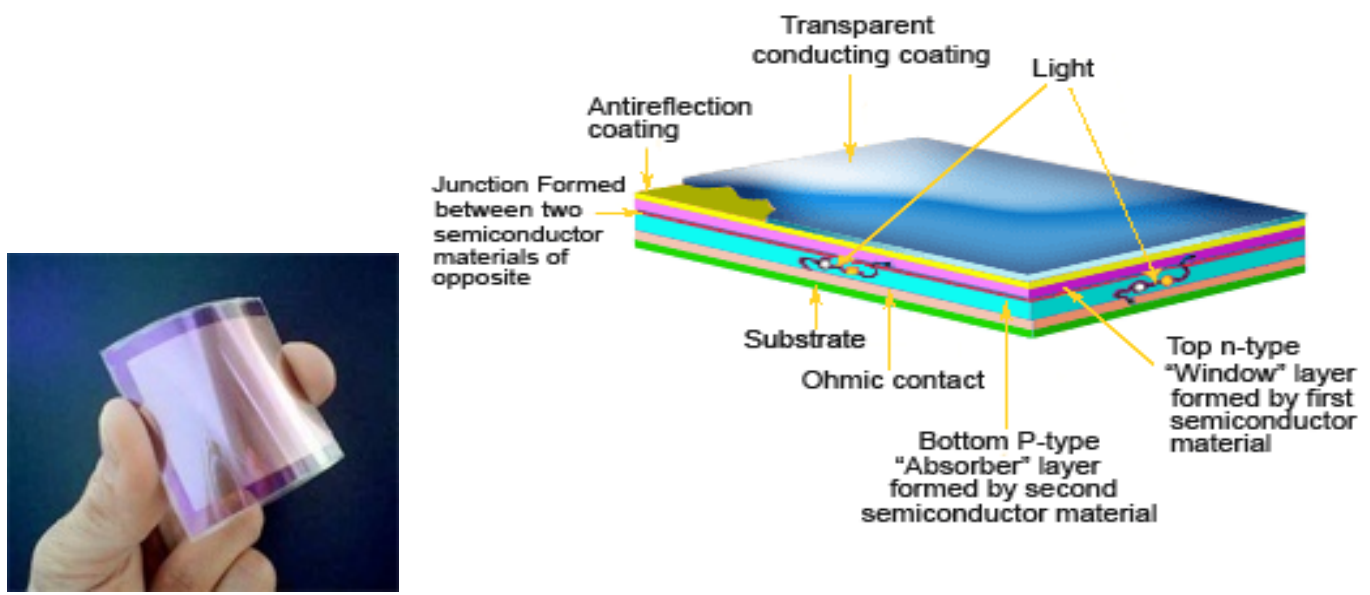

Figure 22. The solar cell of thin film

Thin film panels can be made flexible and light weight by using plastic glazing. Some flexible panels can tolerate a bullet hole without failing. Some of them perform slightly better than crystalline modules under low light conditions. They are also less susceptible to power loss from partial shading of a module.

Lower efficiency means that more space and mounting hardware is required to produce the same power output. Thin film materials tend to be less stable than crystalline, causing degradation over time. The technology is being greatly improved, however, so I do not wish to generalize in this article. We will be seeing many new thin film products introduced in the coming years, with efficiency and warranties that may approach those of crystalline silicon.

If we've used a solar-powered calculator, you've seen a solar cell based on thin-film technology. Clearly, the small cell in a calculator is not big and bulky. Most are about an inch $(2.5 \mathrm{~cm})$ long, a quarter-inch $(0.6 \mathrm{~cm})$ wide and wafer-thin. The thinness of the cell is the defining characteristic of the technology. Unlike silicon-wafer cells, which have light absorbing layers that are traditionally 350 microns thick, thin-film solar cells have light-absorbing layers that are just one micron thick. A micron, for reference, is one-millionth of a meter $(1 / 1,000,000 \mathrm{~m}$ or $1 \mu \mathrm{m})$.

Thin-film solar cell manufacturers begin building their solar cells by depositing several layers of a light-absorbing material, a semiconductor onto a substrate -- coated glass, metal or plastic. The materials used as semiconductors don't have to be thick because they absorb energy from the sun very efficiently. As a result, thin-film solar cells are lightweight, durable and easy to use. There are three main types of thin-film solar cells, depending on the type of semiconductor used: amorphous silicon (a-Si), cadmium telluride (CdTe) and copper indium gallium desalinide (CIGS). Amorphous silicon is basically a trimmed-down version of the traditional silicon-wafer cell. As such, a-Si is well understood and is commonly used in solar-powered electronics. It does, however, have some drawbacks.
One of the biggest problems with a-Si solar cells is the material used for its semiconductor. Silicon is not always easy to find on the market, where demand often exceeds supply. But the a-Si cells themselves are not particularly efficient. They suffer significant degradation in power output when they're exposed to the sun. Thinner a-Si cells overcome this problem, but thinner layers also absorb sunlight less efficiently. Taken together, these qualities make a-Si cells great for smaller-scale applications, such as calculators, but less than ideal for larger-scale applications, such as solar-powered buildings. Promising advances in non-silicon thin-film PV technologies are beginning to overcome the issues associated with amorphous silicon. On the next page, we'll take a look at CdTe and CIGS thin-film solar cells to see how they compare.

\subsection{Working}

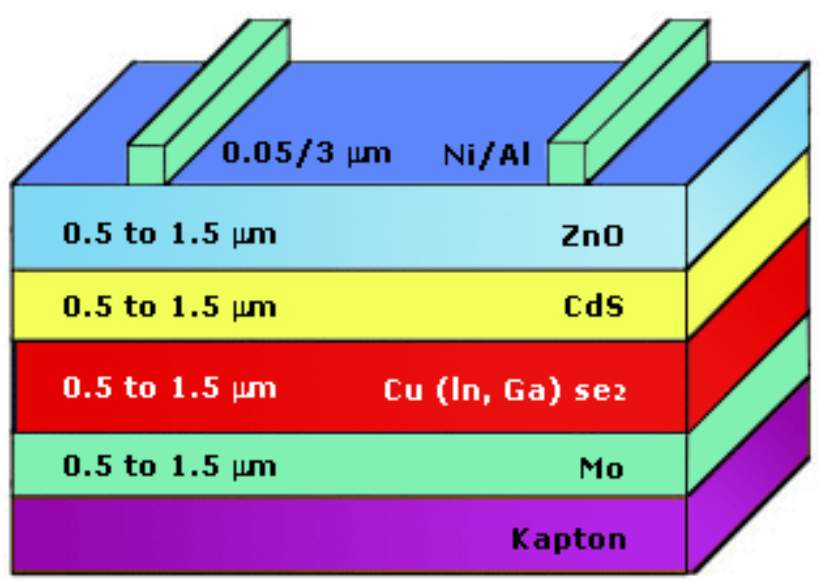

Figure 23. Layer arrangement of thin film solar cell

The basic substance of a photovoltaic cell is semiconductors. The semiconductor doped with phosphorus develops an excess of free electrons (usually called $\mathrm{N}$ type material) and a semiconductor doped with boron, gallium or indium develop a vacancy( called holes) 
and this doped materials known as $\mathrm{P}$ type materials. These $\mathrm{n}$ type and $\mathrm{p}$ type materials combine (join) to form a Photo voltaic cell. During the absence of light, a very small amount of atoms are excited and move across the junction. This causes a small voltage drop across the junction. In the presence of light, more atoms are excited and flow through the junction and cause a large current at the output. This current can be stored in a rechargeable battery and used for several applications based on our requirement.

The old solar panel technology use silicon semiconductor for the production of $\mathrm{p}$-type and n-type layers and has several disadvantages. But in the case of Thin Film Layer technology, the silicon semiconductor materials are replaced by either cadmium telluride (Cute) or copper indium gallium deselenide (CIGS).

\subsection{Advantages}

- $\quad$ Easy to handle

- More flexible than conventional solar cells

- Available as thin wafer sheets

- Cheaper than traditional panels

- Instead of thick silicon wafers, thin-film solar cells only just enough photovoltaic material to cover the surface of the substrates. Solar panels made of amorphous silicon use less amounts of silicon compared to both mono- and polycrystalline solar panels.

- The manufacturing process we use to produce thin-film amorphous silicon solar cells is relatively simple, easy to scale, and only requires small amounts of silicon. Thin-film amorphous silicon solar cells are therefore generally cheaper than those made of crystalline silicon.

- Can be made flexible and lightweight- A flexible thin-film module enables us be much more creative when it comes to applications. They can be placed on curved surfaces and will probably in the future be incorporated into clothing! The strength and flexibility of thin film solar panels are highly dependent on the surface where it is attached.

- Thin film solar panels perform better under worse lighting conditions and deal better with partial coverage such as shade, dirt and snow than crystalline solar panels.

\subsection{Disadvantages}

- Less efficiency (20 to 30\% of light converted into electricity)

- Complex structure

- Need to be very careful in handling

- Can't be used in astronomical devices.

- Lower efficiency and uncertain durability.

- Thin-film solar panels do not last as long as mono- and polycrystalline solar panels. The warranty issued by the manufacturer is therefore usually lower than with crystalline solar panels.
- Amorphous thin-film solar cells only have a conversion rate of $6-12 \%$. However, since the technology is relatively new, efficiency rates of thin-film solar panels are expected to steadily getting closer to those of crystalline panels.

- Solar panels made of this material is therefore the least space-efficient, which means that you have to cover significantly more surface for the same power output in comparison to crystalline silicon. They are also much heavier.

\subsection{Applications}

- $\quad$ Electronic powering circuits

- Home light applications

- Used in Solar fields

\subsection{Silicon Thin Film Solar Cells}

Silicon thin film solar cells are made by chemical vapor deposition from silane gas and hydrogen gas. This results in either:1. Amorphous silicon (a-Si or a-Si:H) 2. Protocrystalline silicon or 3. Nano-crystalline silicon (nc-Si or nc-Si:H), also called micro-crystalline silicon. The solar cells made from these materials generally have lower energy conversion efficiency than bulk silicon cells. They are however less expensive to produce and subsequently cheaper at point of retail sale. Amorphous silicon has a higher band-gap $(1.7 \mathrm{eV})$ than crystalline silicon (c-Si) $(1.1 \mathrm{eV})$, which means it absorbs the visible part of the solar spectrum more strongly than the infrared portion of the spectrum. As nc-Si has about the same band-gap as c-Si, the nc-Si and a-Si can advantageously be combined in thin layers, creating a layered cell called a tandem cell. The top a-Si cell absorbs the visible light and leaves the infrared part of the spectrum for the bottom cell in nano-crystalline Si. Solutions to overcome the limitations of thin-film crystalline silicon have been recently developed. Light trapping schemes allow weakly absorbed long wavelength light to traverse the film several times significantly enhancing the absorption of sunlight in the thin silicon films.

Thermal processing techniques can significantly enhance the crystal quality of the silicon and thereby lead to higher efficiencies of the final solar cells. A silicon thin film technology is being developed for building integrated photovoltaic. This will take the form of semi-transparent solar cells which can be applied as window glazing.

\subsection{Cadmium Telluride Solar Cell (CdTe)}

A cadmium telluride is an efficient light-absorbing material for thin-film cells. Compared to other thin-film materials, CdTe is easier to deposit and more suitable for large-scale production. Despite much discussion of the toxicity of CdTe-based solar cells, this is the only technology (apart from amorphous silicon) that can be delivered on a large scale. The perception of the toxicity of CdTe is based 
on the toxicity of elemental cadmium, a heavy metal that is a cumulative poison. However it has been shown that the release of cadmium to the atmosphere is lower with CdTe-based solar cells than with silicon photovoltaic and other thin-film solar cell technologies.

\subsection{Copper-Indium Selenide (CuInSe2)}

These semiconductors are especially attractive for thin film solar cell application because of their high optical absorption coefficients and versatile optical and electrical characteristics which can in principle be manipulated and tuned for a specific need in a given device. CIS is an abbreviation for general chalcopyrite films of copper indium selenide (CuInSe2) and CIGS mentioned below is a variation of CIS.

CIS films (no Ga) achieved greater than 14\% efficiency. Manufacturing costs of CIS solar cells at present are high when compared with amorphous silicon solar cells but continuing work is leading to more cost-effective production processes. When gallium is substituted for some of the indium in CIS, the material is referred to as CIGS, or copper indium/gallium diselenide, a solid mixture of the semiconductors $\mathrm{CuInSe} 2$ and $\mathrm{CuGaSe} 2$, often abbreviated

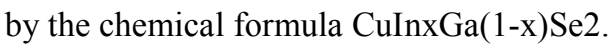

Unlike the conventional silicon based solar cell, which can be modelled as a simple p-n junction, these cells are best described by a more complex hetero-junction model. The best efficiency of thin film solar cells as of March 2008 was $19.9 \%$ with CIGS absorber layer. Higher efficiencies (around 30\%) can be obtained by using optics to concentrate the incident light or by using multi-junction tandem solar cells. The use of gallium increases the optical band-gap of the CIGS layer as compared to pure CIS, thus increasing the open-circuit voltage, but decreasing the short circuit current. In another point of view, gallium is added to replace indium due to gallium's relative availability to indium. The atomic ratio for Ga in the $>19 \%$ efficient CIGS solar cells is $\sim 7 \%$, which corresponds to a band-gap of $\sim 1.15 \mathrm{eV}$. CIGS solar cells with higher Ga amounts have lower efficiency. For example, CGS solar cells which have a band-gap of $\sim 1.7 \mathrm{eV}$ have a record efficiency of $9.5 \%$ for pure CGS and $10.2 \%$ for surface-modified CGS.

For comparison, silicon solar cells used up 33\% of the world's electronic grade silicon production in 2006. Nano-solar claims to waste only $5 \%$ of the indium it uses. That being said, indium can easily be recycled from decommissioned PV modules. So the number of recombination sites in the film are reduced which benefits the quantum efficiency and thus the conversion efficiency.

\subsection{Gallium Arsenide (GaAs) Multi-junction Cells}

These multi-junction cells consist of multiple thin films produced using Metal-organic vapor phase epitaxy. A triple-junction cell, for example, may consist of the semiconductors: GaAs, Ge, and GaInP2. Each type of semiconductor will have a characteristic band gap energy which, loosely speaking, causes it to absorb light most efficiently at a certain color, or more precisely, to absorb electromagnetic radiation over a portion of the spectrum. The semiconductors are carefully chosen to absorb nearly the entire solar spectrum, thus generating electricity from as much of the solar energy as possible.

GaAs based multi-junction devices are the most efficient solar cells to date, reaching a record high of $40.7 \%$ efficiency under solar concentration and laboratory conditions. This technology is currently being utilized in the Mars rover missions. Tandem solar cells based on monolithic, series connected, gallium indium phosphide (GaInP), gallium arsenide GaAs, and germanium Ge pn junctions, are seeing demand rapidly rise. The Dutch Radboud University Nijmegen set the record for thin film solar cell effiency using a single junction GaAs to $25.8 \%$ in August 2008 using only 4 $\mu \mathrm{m}$ thick GaAs layer which can be transferred from a wafer base to glass or plastic film.

\subsection{Dye-Sensitized Thin Film Solar Cells (DSSC)}

Typically a ruthenium metal-organic dye ( $\mathrm{Ru}$-centered) is used as a mono-layer of light-absorbing material. The dye-sensitized solar cell depends on a mesoporous layer of nano-particulate titanium dioxide to greatly amplify the surface area $\left(200-300 \mathrm{~m}^{2} / \mathrm{g} \quad \mathrm{TiO}_{2}\right.$, as compared to approximately $10 \mathrm{~m}^{2} / \mathrm{g}$ of flat single crystal). The photo-generated electrons from the light absorbing dye are passed on to the n-type $\mathrm{TiO}_{2}$, and the holes are passed to an electrolyte on the other side of the dye. The circuit is completed by a redox couple in the electrolyte, which can be liquid or solid. This type of cell allows a more flexible use of materials, and is typically manufactured by screen printing and/or use of Ultrasonic Nozzles, with the potential for lower processing costs than those used for bulk solar cells.

However, the dyes in these cells also suffer from degradation under heat and UV light, and the cell casing is difficult to seal due to the solvents used in assembly. In spite of this, DSSC is a popular emerging technology with some commercial impact forecast within this decade.

\subsection{Organic/Polymer Thin Film Solar Cells}

Organic solar cells and Polymer solar cells are built from thin films (typically $100 \mathrm{~nm}$ ) of organic semiconductors such as polymers and small-molecule compounds like poly-phenylene vinylene, copper phthalocyanine (a blue or green organic pigment) and carbon fullerenes and fullerene derivatives such as PCBM.

Energy conversion efficiencies achieved to date using conductive polymers are low compared to inorganic materials, with the highest reported efficiency of $6.5 \%$ for tandem cell architecture. However, these cells could be beneficial for some applications where mechanical flexibility and disposability are important. These devices differ from inorganic semiconductor solar cells in that they do not rely on the large built-in electric field of a PN junction to separate the electrons and holes created when photons are 
absorbed. The active region of an organic device consists of two materials, one which acts as an electron donor and the other as an acceptor.

When a photon is converted into an electron hole pair, typically in the donor material, the charges tend to remain bound in the form of an exciton, and are separated when the exciton diffuses to the donor-acceptor interface. The short exciton diffusion lengths of most polymer systems tend to limit the efficiency of such devices. Nano-structured interfaces, sometimes in the form of bulk hetero-junctions, can improve performance.

Thin film solar cells are likely to become a standard feature in the future of building integrated solar power.

Researchers have made an important breakthrough in the use of continuous flow micro-reactors to produce thin film absorbers for solar cells -- an innovative technology that could significantly reduce the cost of solar energy devices PV experts generally agree that crystalline silicon will remain the "premium" technology for critical applications in remote areas. Thin film will be strong in the "consumer" market where price is a critical factor.

\section{Sizing the Solar System}

\subsection{Which Solar Panel Type Should We Choose?}

A. Lowest Cost:

The lowest cost category is probably the largest of them all. If you want the lowest cost per rated power, or in other words, pay as little as possible to generate electricity, we should investigate if thin-film solar panels match up nicely with the crystalline solar panels and could be your best pick.

\section{B. Limited Space:}

For those who don't have enough space for thin-film solar panels (or want to limit the amount of space their PV-system takes up), or if they are simply not offered in your area, a crystalline-based solar panel is usually the way to go. The manufacturer usually offers a set of different solar panel sizes. A 180, 200 and 220 watt rated solar panels are usually physically the same size. These are manufactured in exactly the same way, but under- or over performed during the testing-phase, hence ended up in different power output categories. If size is of concern, you should go for the highest rated output for a particular physical size.

Both mono- and polycrystalline solar panels are good choices and offer similar advantages. Even though polycrystalline solar panels tend to be less space-efficient and mono crystalline solar panels tend to output more power, this is not always the case. It would be nearly impossible to recommend one or the other by not examining your situation closer.

Mono crystalline solar panels are typically slightly more expensive, and are therefore typically slightly more space-efficient due to higher energy efficiencies. In other words, a $120 \mathrm{~W}$ mono crystalline and a $120 \mathrm{~W}$ polycrystalline solar panel would technically generate equal amounts of electricity, but the one made of mono crystalline silicon usually comes out on top when it comes to space-efficiency.

\section{Cost vs. Value - Other Factors}

As not all panels and module manufacturers are equal, there are a variety of other factors that should influence your purchase decision rather than focusing solely on cost.

\section{Tolerance}

This is the range a panel will either exceed or not meet its rated power. For example, a solar module may have 'nameplate' wattage of 200 watts; but due to quality control issues, may in reality only be 195 watts. A positive tolerance rating means the panel will not only generate 200 watts, but perhaps more under standard testing conditions.

\section{E. Temperature co0-efficient}

The temperature co-efficient rating is important to determine what the impact heat has on a solar panel's operation.

\section{F. Conversion efficiency}

The efficiency of how a solar panel converts light into electrical energy will determine how much power your system generates.

\section{G. Embodied energy}

Another important aspect to look at is the embodied energy of the solar panel - that is how energy intensive the production of the panel was and how quickly it will have paid itself back by producing more energy.

\section{H. Durability / Longevity / Warranty}

The durability or longevity of a solar panel is important for a number of reasons - it can be an indicator of the manufacturer's confidence in its products. Reputable solar panels will have warranty a period of 25 years. All of our key panels.

However, an important point to remember about warranty is that it will only be honored for as long as the company operates. It's another reason to select a well-known brand of solar panel rather than an obscure low-cost brand that may disappear overnight. As you most likely won't be able to buy panels directly from the manufacturer, your selection of retailer is also important. Choose a company that is a service agent for solar panel warranty work for the particular manufacturer you select so if you do strike a problem, the turnaround time to a resolution will be far faster.

\section{Size and Watts}

The size of the solar panel in Watts will directly affect the cost, as solar panels are usually priced (and compared) in dollars per Watt. Watts are related to the output of each panel; meaning a 100Watt panel under ideal conditions will generate 100 Watts of electricity each hour and a 200 Watt panel will generate 200 Watts each hour. Therefore expect to pay double the price for the 200 Watt panel, compared to the cost of a 100 Watt panel. 
The output of a panel also affects the physical size of the panel, meaning the 200Watt panel will be larger in size to the $100 \mathrm{Watt}$ panel. The type of solar cells used in its production also determines the size of the solar panel. They key issue to consider is that your system sizing is enough to power your appliances, and that the solar panels will physically fit in the area you wish to install them.

Your northerly facing roof space is very valuable solar power real estate, so you'll need to consider carefully your future plans. If you believe at some stage you will wish to add on more panels, you need to ensure you'll have the space to do so, otherwise you may find you'll need to replace existing panels well before the end of their serviceable life.

\section{J. Types of solar cells used}

Mono crystalline silicon is the most efficient and produces the smallest solar cells, and therefore the smallest panels. Mono-crystalline solar panels also tend to cost the most. An example of a mono-crystalline solar panel is the Daqo DQ190MFAa/b190 watt module

Polycrystalline(or multi-crystalline) silicon produces the next most efficient type of solar cell and is the most popular choice as it provides an excellent balance of performance and cost. Recent improvements in polycrystalline panel technology are bringing these modules closer to mono-crystalline in size, efficiency and heat tolerance characteristics. The European market has now adopted polycrystalline as the standard.

Amorphous (or thin-film) silicon uses the least amount of silicon. While some thin film panels are among the least efficient solar cells, solar panels offer the highest conversion efficiency of any mass-produced thin-film module.

- Solar Panel Shopping Checklist

In summary, these are the major points you should bear in mind when buying solar panels aside from cost:

- Consider how the module is manufactured and the materials used.

- Research how the panels perform in real world situations - including positive tolerance,

- Temperature co-efficient rating and efficiency.

- Compare the warranty details of the solar panels you are considering.

- Learn more about the company that manufactures the panels

\subsection{Solar System sizing consideration factor}

Require data are following -

- The daily or hourly load requirements during a typical year.

- The required security of supply, taking into account the back-up source, (if any).

- The mean daily irradiation in the plane of the array at the chosen site for every month of a typical year.

- The maximum number of consecutive sunless days likely to be experienced.
- The mean daily ambient temperature for every month of a typical year.

- The estimated cell temperature rise above ambient of the modules in the array.

- Typical current-voltage characteristics of the module at various irradiances.

- The selected DC bus voltage.

- The maximum allowable depth of discharge of the battery.

- The estimated percentage energy losses in the battery, power conditioning equipment and control system.

- The estimated losses in the array from module mismatch, cables and voltage drop across blocking diodes.

- The estimated losses from dust and shading.

- Calculated the global position.

- Considering the categories of solar modules structure.

- Choosing the type of solar charge controller such as voltage regulated charger, PWM (Pulse wide modulated), MPPT (Maximum Power Point Tracker).

- Choosing the type of solar panel such as mono-crystalline, poly-crystalline, thin film.

In practice, designing a $\mathrm{PV}$ system depends if it is off-grid or grid-tied.

Off-grid systems require a rigorous design, often with several iterations to optimize the number of modules, batteries, and stand-by generators, if necessary, to minimize system costs. Loads must be carefully calculated.

Grid-tied systems generally are sized by one of two methods:

i. How big of a system is possible with the available budget, i.e. budget constrained.

ii. How big of a system is possible given a limited area, i.e. area constrained.

NOTE: Systems rarely are large enough to match the load.

Approach is generally used. Also, the PV industry is marketing pre-engineered packages of varying sizes.

\subsection{Off-Grid Design Example}

- $\quad$ Step 1: Determine the DC Load.

\begin{tabular}{|c|c|c|c|}
\hline DC Device & Device Watts & $\begin{array}{c}\text { Hours of Daily } \\
\text { Use }\end{array}$ & $\begin{array}{c}\text { DC Watt-Hrs } \\
\text { per Day }\end{array}$ \\
\hline Refrigerator & 120 & 24 & 2880 \\
\hline $\begin{array}{c}\text { Lighting fixtures } \\
\text { and fans }\end{array}$ & 450 & 4 & 1800 \\
\hline Others Device & 80 & 8 & 640 \\
\hline \multicolumn{3}{|c|}{ Total load (Watt-Hrs /Day) } & 5320 \\
\hline
\end{tabular}

- Step 2: Determine the AC Load, Convert to DC

\begin{tabular}{|c|c|c|c|}
\hline AC Device & Device Watts & $\begin{array}{c}\text { Hours of } \\
\text { Daily Use }\end{array}$ & $\begin{array}{c}\text { AC Watt-Hrs } \\
\text { per Day }\end{array}$ \\
\hline Water pump & 746 & 3 & 2238 \\
\hline Television & 80 & 6 & 480 \\
\hline Others Device & 150 & 3 & 450 \\
\hline \multicolumn{2}{|c|}{ Total load (Watt-Hrs/Day) } & 3168 \\
\hline
\end{tabular}

Total AC Watt-hrs/Day 3,168 Divided by 0.85 (Inverter, losses $)=3,728$ (DC watt-hrs/Day) 
- Step 3: Determine the Total System DC Load

- Total System Load 9,048 Whrs/Day

- Step 4: Determine Total DC Amp-hours/Day

- Total System Load / System Nominal Voltage

$=(9,048 \mathrm{Whrs} /$ Day $) / 12$ Volts $=754$

Amp-hrs/Day

- Step 5: Determine Total Amp-hr/Day with Batteries

- Total Amp-hrs/Day X 1.2(Losses and safety factor) $754 \mathrm{Amp}$-hrs/Day X 1.2 $=904.8$ or 905 Amp-hrs/Day. (Assume: Losses and safety factor of battery is 1.2).

- Step 6: Determine Total PV Array Current

- Total Daily Amp-hr requirement / Design Insolation*

- 905 Amp-hrs / 5.0 peak solar hrs =181 Amps.

- Insolation Based on Optimum Tilt for Season

- Step 7: Select PV Module Type

- Choose BOSCH Solar Module $\mu \mathrm{m}-\mathrm{Si}$, Performance class: $100 \mathrm{Wp}$.

- $\quad$ Maximum Power Point (Pmpp) : $100(\mathrm{Wp})$

- Maximum Power Point Voltage (Vmpp) : $98 \mathrm{~V}$

- Maximum Power Point Current (Impp) : 1.02 (A)

- Open Circuit Voltage: 129 (V)

- Short Circuit Current : 1.34 (A)

- Initial Open Circuit Voltage: $131(\mathrm{~V})$

- Initial Short Circuit Current: 1.37(A).

- Step 8: Determine Number of Modules in Parallel Total PV Array Current + (Total Power Conversion losses) / (Module Operating Current) X (Module Derate Factor)
199.1 Amps / (1.02 Amps/Module $)(0.90)=216.88$ modules

Use 217 Modules

Total power conversion losses depend on quality of thin film charge controller, if user chooses enhanced quality charge controller then total power conversion losses will be decreased and reduce the no of solar modules.

- Step 09: Determine Minimum Battery Capacity

[Total Daily Amp-hr/Day with Batteries (Step 5) X Desired Reserve Time (Days)] / Percent of Usable Battery Capacity (905 Amp-hrs/Day X 3 Days) $/ 0.80=3393.75$ Amp-hrs or 3394 Amp-hrs.

- Step 10: Choose a Battery

Use a Flooded Lead Acid Battery

Nominal Voltage $=12$ Volts

Rated Capacity $=220$ Amp-hrs

- Step 11: Determine Total Number of Batteries

Total Battery capacity/Rated capacity $=(3394 / 220)=$ 15.43 No of battery $\approx 15$ No of battery.

\section{Solar Home System (SHS)}

\subsection{Introduction}

The Solar Panels collect energy from the sun and turn it into electricity. The Inverter converts DC electricity from the Solar Panels and turns it into AC electricity that we use in our homes. Solar power system with Battery backup stores some of the electricity harnessed by the PV solar panels in a battery or batteries. The battery is connected to defined circuits in the house and supply electric.

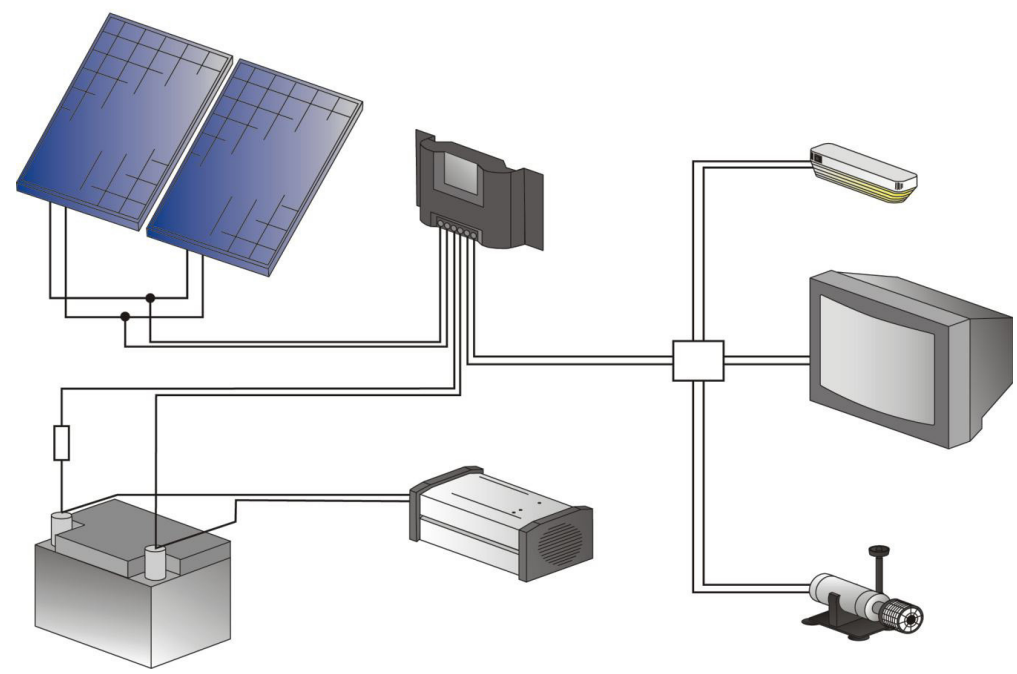

Figure 24. Solar Home System and its different connection. 


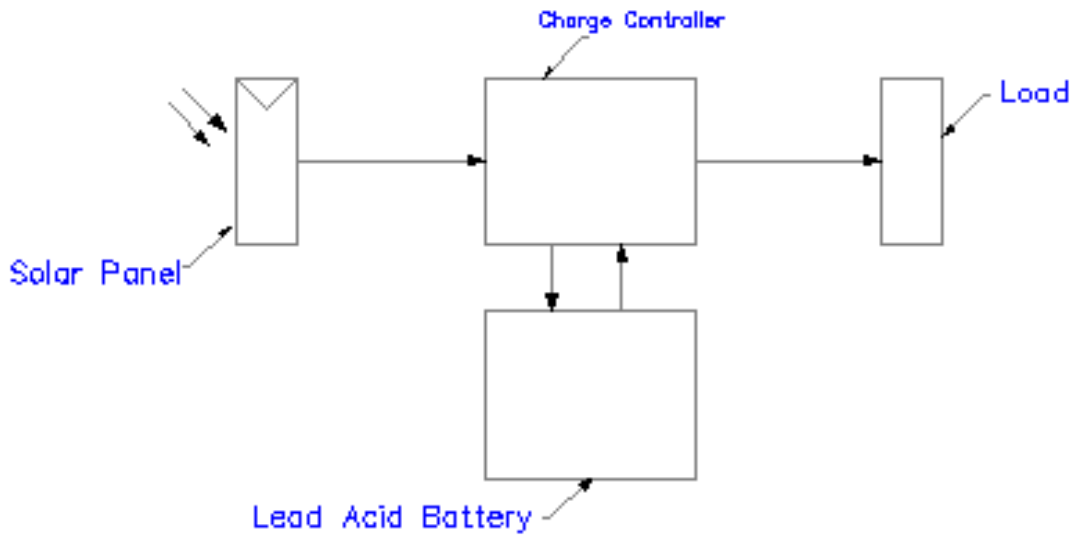

Figure 25. solar home system components.

Power to these critical circuits when event of utility outage occurs. The beauty of solar power is it is a free source of energy. Historically, the cost of capturing and maintaining solar power wasn't cheap, but this has changed dramatically in the last ten years. Systems are now much more efficient, with the total cost usually involved in the purchase and installation. Depending on the system, there is almost no maintenance cost and most systems have a 40 or 50 year life span.

A solar home System is comprised of the following components:

- Solar(PV) Panels

- Solar charge controller

- Inverter

- Battery

- Mounting system

\subsection{Solar (PV) Panels}

Solar panels are a great way to generate clean and renewable electricity to power remote appliances, or even the average home. The Solar (PV) Panels consist of dozens of small, square - shaped solar cells which can convert light directly into electricity.

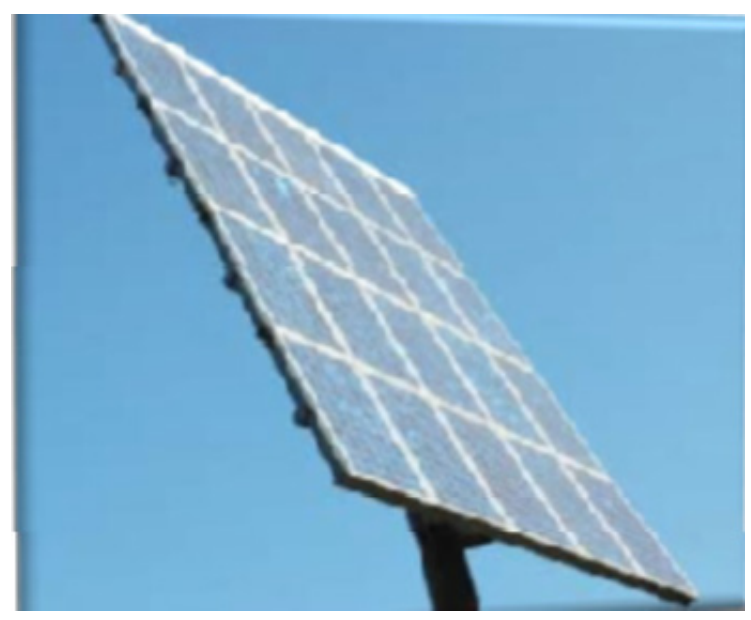

Figure 26. Solar panel array.
Photovoltaic cells can be aligned as an array, as shown in the image to the top of this page.

There are many advantages of using a solar cell array, with various panels fitted along a mounting system. One of the main advantages is that we are able to combine various numbers of cells to provide a greater output of electricity, and this method makes solar electricity a viable option to power small homes and businesses.

The increasing efficiency of solar energy technologies means we are able to purchase and install panels, knowing we are likely to receive an efficient way of harnessing energy from the sun's rays to turn into electricity for use in our homes. It is quite possible for a household to run completely off photovoltaic electricity from the use of solar panels, yet this is unlikely in most cases. The costs involved with supplying a whole house with electricity from solar energy would be quite high for the average homeowner. However, the use of solar electricity in the average home is still able to provide a substantial amount of electricity, reducing future energy bills.

\subsection{Inverter}

An inverter is a device that changes a $12 \mathrm{v}$ dc battery into 120 volts ac useable household electricity. We can run our Lights, TV set, mobile charger, computers, power tools etc. The 12 volts is stepped up to 120 to 125 volts dc, and then the $\mathrm{dc}$ is converted into 120 volts ac by a very special design of ours. We can run light bulbs with $120 \mathrm{v}$ dc but to run our TV, VCR etc.. The $120 \mathrm{v}$ de needs to be converted to AC. Which is no problem, we can do it by electronic switching or use our new mechanical can oil filled canister type commutator design. All we need is to use is a high efficient electric motor that runs in the milliamps to turn the commutator switching shaft, the oil in the can will keep the commutator from sparking! We can even convert an old DC motor from an auto junk yard, rewire it and fill it with oil just as well. We can adjust the speed to get the desired $60 \mathrm{~Hz}$.

These plans are not as step by step as many of our other plans but they are well worth the money and loaded with information for anyone wanting to build an inverter. 
Very easy to build! Can be used as a modified sign wave or pure sine wave if we allow the DC to be pulsed into a large transformer and choke. By doing it this way we should not need an oil switching commutator canister to turn the DC to $\mathrm{AC}$, the transformer will do that for us. 240v could be made by using $2-12 \mathrm{v} d c$ batteries in series / inputting $24 \mathrm{v} d c$.

\subsection{Mounting System}

The mounting system securely attaches PV panels to the roof or, in some cases, on the ground. It is designed to provide support and balance. Some common mounting system -

$\begin{array}{ll}\text { - } & \text { Roof Mount } \\ \text { - } & \text { Pround Mount Mount } \\ \text { - } & \text { Building Integrated Photovoltaic (BIPV) }\end{array}$

\section{Solar Charge Controllers}

\subsection{Introduction}

A charge controller, or charge regulator is similar to the voltage regulator. It regulates the voltage and current coming from the solar panels going to the battery. Most "12 volt panels put out about 16 to 20 volts, so if there is no regulation the batteries will be damaged from overcharging. Most batteries need around 14 to 14.5 volts to get fully charged.

Since batteries represent a substantial cost factor for example in case of a typical is land house of about $15-20 \%$ of initial investments, which can rise over $50 \%$, if one considers the necessity for a repeated replacement of the battery over the lifetime of the total system. Therefore it is aimed to achieve, by suitable charging and supervision strategies, as long life of the battery as possible under given operating conditions. Experiences from a great deal of systems show however that with the presently used technique the obtained life lasting with $2-4$ years is clearly shorter than the expected values of $5-8$ years. The determination of the responsible causes and the derived, from them, development of new concepts and system components are thus important assignments in the future.

In the following, basic principles of common charge controllers are described. The theme is limited thereby to charge controllers for the lead acid batteries used in larger systems.

\subsection{Basic principles of charge controllers}

Basic function of a charge controller is operating the battery within the operation limits given by the manufacturer regarding overcharging or deep discharge. Moreover, a charge controller can execute automatically maintenance like regular equalizing charge or gassing charge as well as inform the user about the status of the system with appropriate displays.

Simple charge controllers have only one voltage threshold for the maximum charge voltage: this value should be adjusted to $2.3 \mathrm{~V} /$ cell with the temperature $20{ }^{\circ} \mathrm{C}$. The maximum charge voltage must be calibrated regarding the temperature with a correction value of $-4 \ldots-6 \mathrm{mV} /{ }^{\circ} \mathrm{C}$, if this deviates by more than $5{ }^{\circ} \mathrm{C}$ from the reference value.

More expensive charge controllers have several voltage thresholds. The strategies were rather empirically established and consist i.e. of a gassing charge within a certain 4 - week interval as well as after each deep discharge. The total gassing time is limited here on 10hours per month. During gassing phase the battery voltage is limited at $2.5 \mathrm{~V} /$ cell, subsequently at $2.35 \mathrm{~V} /$ cell.

\subsection{Switching controllers}

Against overcharging of batteries a protection is always planned with the solar charge controllers: the regulating unit is either totally closed or completely opened. Ideally the developing dissipated heat is zero in both cases since either current or voltage at the regulating unit is zero.

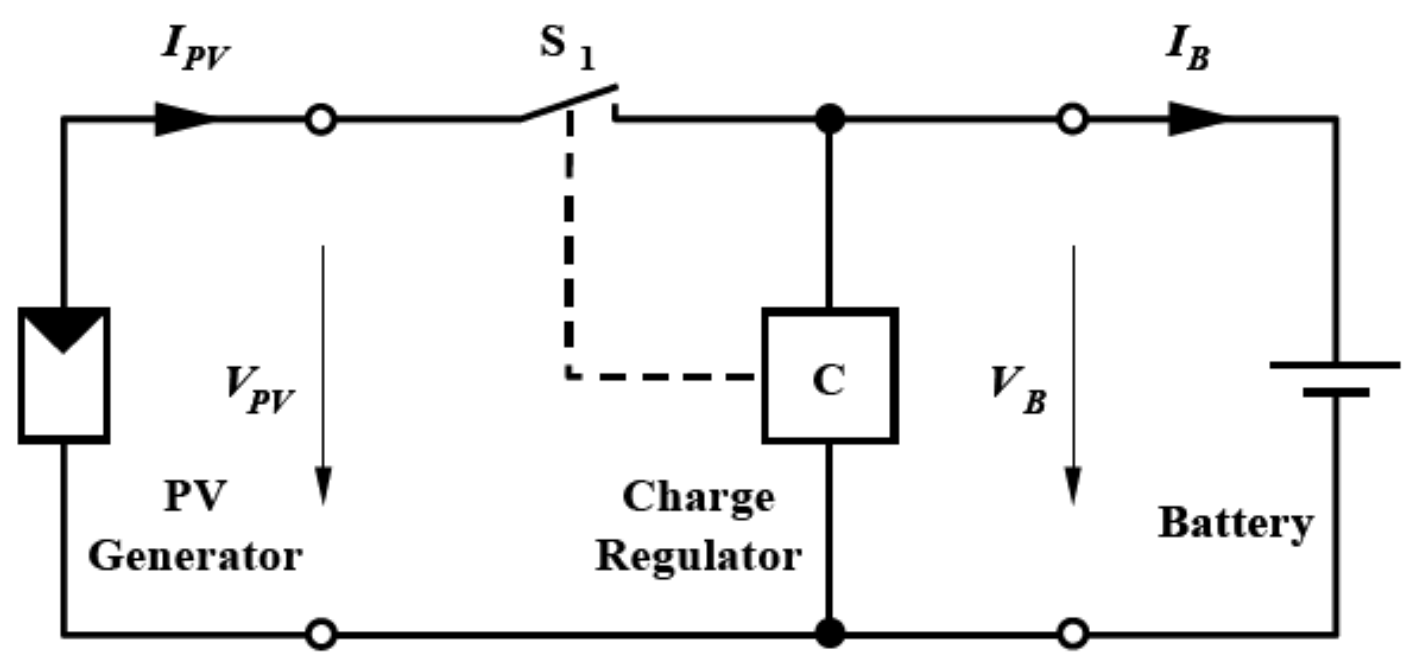

Figure 27. Principle of series controller 
In case of the series controller (Figure 27), the current flow is influenced by a regulating unit, namely switch S1, which is positioned in series to the PV generator. While relays were quite used as switches in the past, they are today almost exclusively replaced by semiconductor switches such as MOSFET's or IGBT's. It is to the series charge controller's advantage that besides PV generators also other, not short - circuit proof, energy converters such as wind generators can be connected. As disadvantage higher power losses were claimed to the series charge controller - however, this historical statement is not valid any longer after the power semiconductors specified above are available.

Regarding the parallel - or shunt controller (Figures 29) the characteristic of PV generators is applied, namely being able to be short - circuited arbitrarily for a long time. During charging the PV generator current flows through the diode D into the battery. As achieving the maximum charge voltage the PV generator is short - circuited by the regulating unit according to one of the further strategies described below, so that no more charging current can flow.

The diode prevents here, on one hand, the current reversal from the battery into this short circuited path; on the other hand it prevents discharging of the battery to the unlighted PV generator at night.

It is favorable with the shunt controller since it makes a charging current also in the case of a completely discharged battery flow through the diode and thus the system starts reliably. This is however not guaranteed in the case of the series controller with a bad connection design since there is no energy available to turn on the switch.

Moreover, as mentioned before, if the battery is connected to the load, the deep discharge protection (DDP) is required, which is represented by the switch S2 in Figure $6-3$. The hybrid controller represents a modification of the shunt controller, with which in the charging phase the blocking diode is bridged by a switch situated in parallel and the dissipated heat is again minimized. However, it must be emphasized here that this is not relevant to the energy gains for the energy balance of the total system but, in the foreground of discussion, rather the reduction of the developing dissipated heat in the controller that leads to savings at heat sinks and housings, in addition, contributes to an increased reliability.

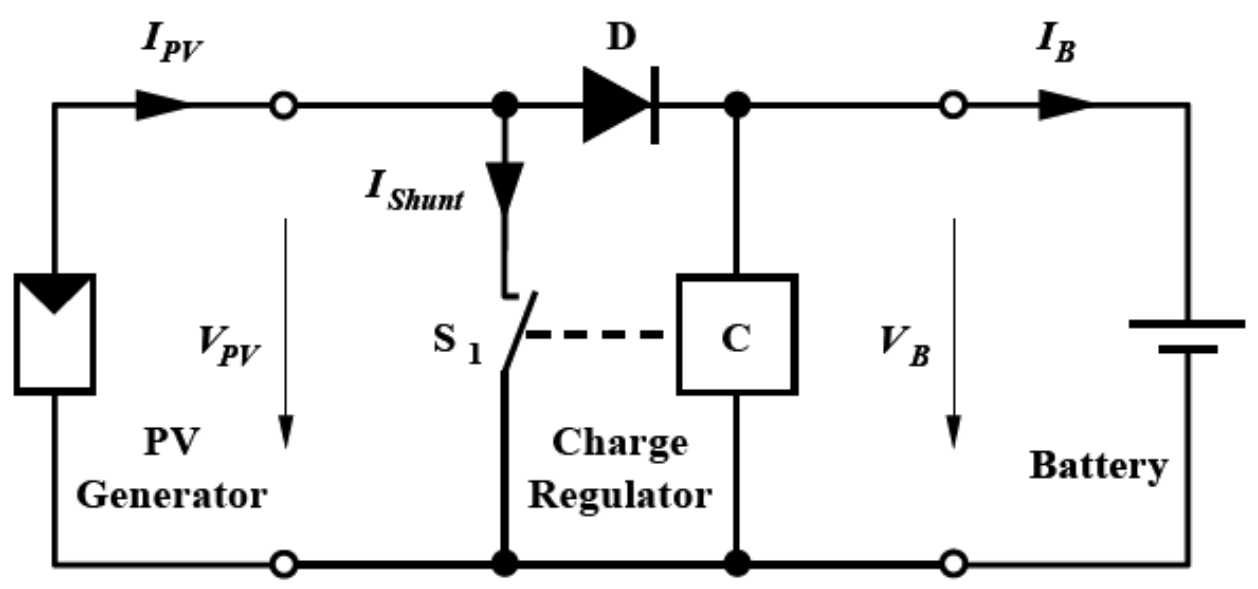

Figure 28. Principle of shunt controller

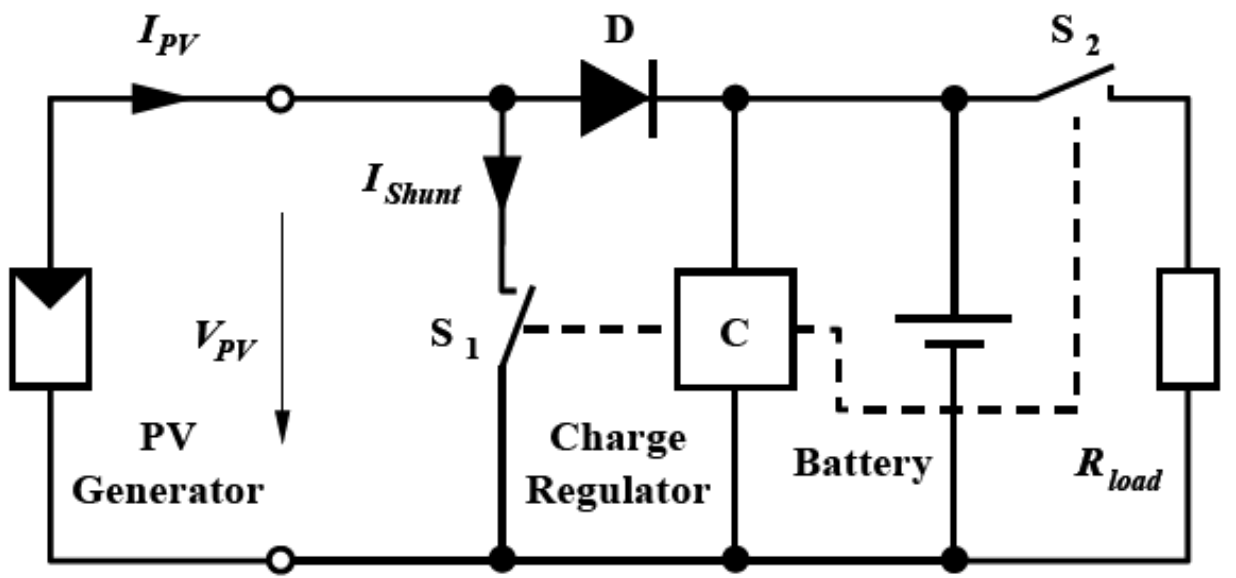

Figure 29. Shunt controller with deep discharge protection (DDP) 


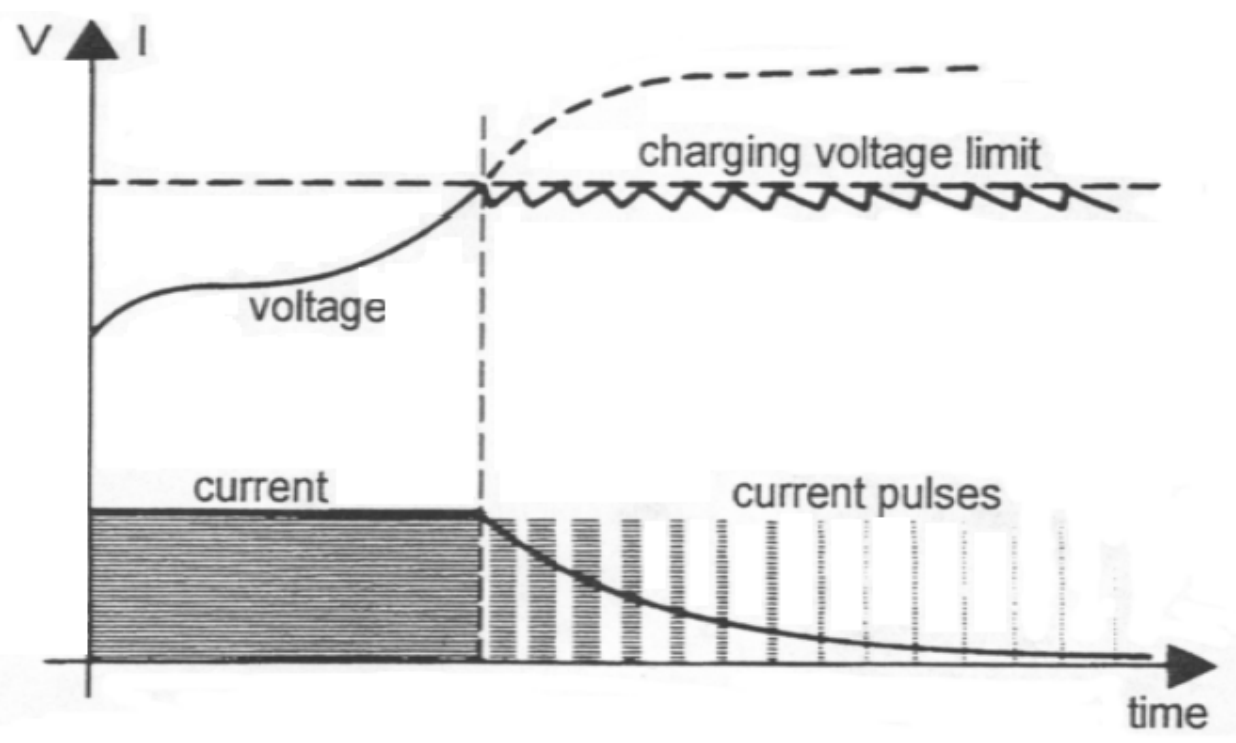

Figure 30. Voltage and current characteristics during charging

In case of higher power of PV generator, the so - called sub array switching is applied; with which the generator is divided into several subfields that operate at a time over assigned sections on a combined battery. Here either all sections can be controlled together by an individual control section or can be however advantageously switched off after a given load strategy, what provides a better control of the total charging current.

An applied method, only sorted in systems of higher voltage, is the so - called partial shunting, with which only one part of the modules interconnected in series is short circuited by an additional connection and thus the generator voltage for a further charging becomes too low.

At the first achieving of the maximum charge voltage a battery is not yet completely charged. It is just fully charged if the whole lead sulphate is converted into lead and leadoxide. To reach the full charging the battery must be further charged for a longer period with constant voltage, whereby the charging current decreases slowly (I - V charging). This behavior can be achieved by suitable control of the regulating unit with the series - and also shunt controller, whereby two realistic possibilities are available:

By means of two - step controller the current, as reaching the maximum charge voltage, is interrupted (by opening the regulating unit of the series controller or closing in the case of shunt controller), thus the battery voltage drops (Fig. 6 4). At this moment a characteristic of the battery has an effect: the battery behaves like a big capacitor. Therefore, the battery voltage does not drop immediately, but rather follows the discharge curve of a capacitor.

As reaching a lower voltage threshold, about some milli-volts, the charging current is again connected and the voltage rises then corresponding to the charging curve of a capacitor.

With increase in state of charge of the battery the resulting charging phases become ever shorter and intervening pauses become longer, so that the average value of charging current decreases as required. The cycle duration of the described phenomenon is not constant, but depends on the state of charge, battery capacity, the charging - or discharge current as well as selected voltage hysteresis: It can therefore vary within the range of milliseconds up to minutes.

The pulse - width - modulated (PWM - ) charge controller operates in principle similarly; However, the switching frequency of the switch is fixed given here by a timer with e.g. $100 \mathrm{~Hz}$. Firstly the full charging current flows here also, whereby during approximation to the maximum charge voltage the relation of charging time to the total cycle time is modified continuously by an appropriate PWM modulator of 1 until 0 . As indicated in the figure above, this has thereby the required reduction of the average charging current as a result.

\subsection{PWM - Pulse Width Modulated Battery Charging}

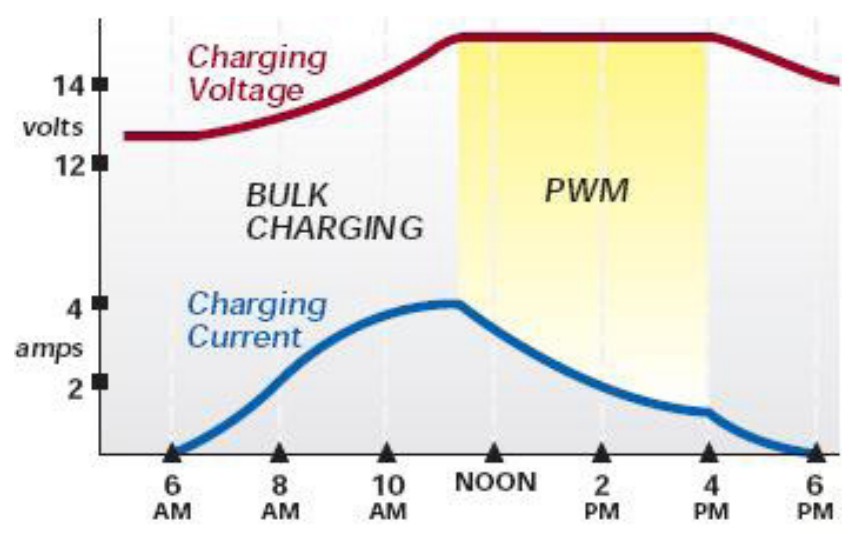

Figure 31. Battery charging curve at PWM mode.

Good quality solar charge controllers are up to $30 \%$ more efficient than basic 'on - off 'regulators as they have provide pulse width modulated (PWM) battery charging. When the voltage of the battery bank reaches the regulation voltage $(14.1 \mathrm{~V})$, instead of stopping charging altogether, the 
patented PWM algorithm reduces the charging current and continues charging slow enough to prevent the battery overheating or gassing.

PWM helps to get the batteries charged up to well over $90 \%$ capacity, extends the life of the battery, and means that more of the power generated by the solar panels is stored. Since the batteries store more energy on average, a smaller battery (or less battery in a battery bank) can be used reducing overall system costs.

\section{A Brief Description of the Project Works}

Developing a Thin Film Solar Charge Controller requires a deep study about solar home system. I have studied component used in solar home system like: battery, PV panel, characteristics of load used which we can use to implement our ideas.

Moreover we discussed with our supervisor about learning. He gave us clear instruction about our forwarding step to implement the thin film solar charge controller.

Firstly, we learn about charge controller procedure in solar home system. Basically charge controller used to control battery charging and discharging limit, which charge controller is perform switching function in solar home system.

Secondly, we study different type of solar charge controller available in present market.

Most of the solar charge controller switching function performs by relay. Only one company implement charge controller using microchip, but their limitation was its current handling capacity were few amperes, i.e. low capacity.

Then we have planned to use op-amplifier (LM324) chip as controller and MOSFET as switching component. Developing an energy meter reader with the combination of op-amplifier and MOSFET can handle more current.

The op-amplifier can be used also to control devices connected with it. We thought that if we use op-amplifiers here we can easily control devices or monitor its status through indicator.

On the above circumstances we have decided to implement our project work with the combination of MOSFET and op-amplifier. The major features we have planned to implement is -

- Handle more current.

- Better controllability.

- Securing the battery and PV panel ensuing proper controlling.

- Dual indication system.

- Cost effective and user friendly.

- High efficient power converter.

- Conversation power loss almost negligible.

- Power conversation above $95 \%$.
We have started our project work by developing controlled signals through op-amplifier and testing through simulation. After the proper debugging of simulation, we stepped to develop the hardware.

On the following chapter we will discuss about the major features of the device and technologies we have used in our project work, development of the microcontroller program coding, testing and debugging it through simulation and the final implementation of the work by developing the hardware.

\section{Features of Major Components}

Our desired goal is basically to create a charge controller. The solution for our difficulty is a feature of on different hardware components interacting with each other to achieve this goal. This chapter introduces these hardware elements briefly and mentions some of the important features they provide to our system.

\subsection{LM324 (Op-Amplifier)}

The LM324 series consists of four independent, high gains; internally frequency compensated operational amplifiers which were designed specifically to operate from a single power supply over a wide range of voltages. Operation from split power supplies is also possible and the low power supply current drain is independent of the magnitude of the power supply voltage.

Application areas include transducer amplifiers, DC gain blocks and all the conventional op amp circuits which now can be more easily implemented in single power supply systems. For example, the LM324 series can be directly operated off of the standard $+5 \mathrm{~V}$ power supply voltage which is used in digital systems and will easily provide the required interface electronics without requiring the additional \pm 15 V power supplies.

\subsubsection{Features of LM324 (Op-Amplifier)}

- Internally frequency compensated for unity gain

- $\quad$ Large DC voltage gain $100 \mathrm{~dB}$

- Wide bandwidth (unity gain) $1 \mathrm{MHz}$ (temperature compensated)

- Wide power supply range: Single supply $3 \mathrm{~V}$ to $32 \mathrm{Vor}$ dual supplies $\pm 1.5 \mathrm{~V}$ to $\pm 16 \mathrm{~V}$

- Very low supply current drain $(700 \mu \mathrm{A})$ — essentially independent of supply voltage

- Low input biasing current $45 \mathrm{nA}$ (temperature compensated)

- Low input offset voltage $2 \mathrm{mV}$ and offset current: 5 nA

- Input common-mode voltage range includes ground

- Differential input voltage range equal to the power supply voltage

- Large output voltage swing $0 \mathrm{~V}$ to $\mathrm{V}+-1.5 \mathrm{~V}$ 


\section{Dual-In-Line Package}

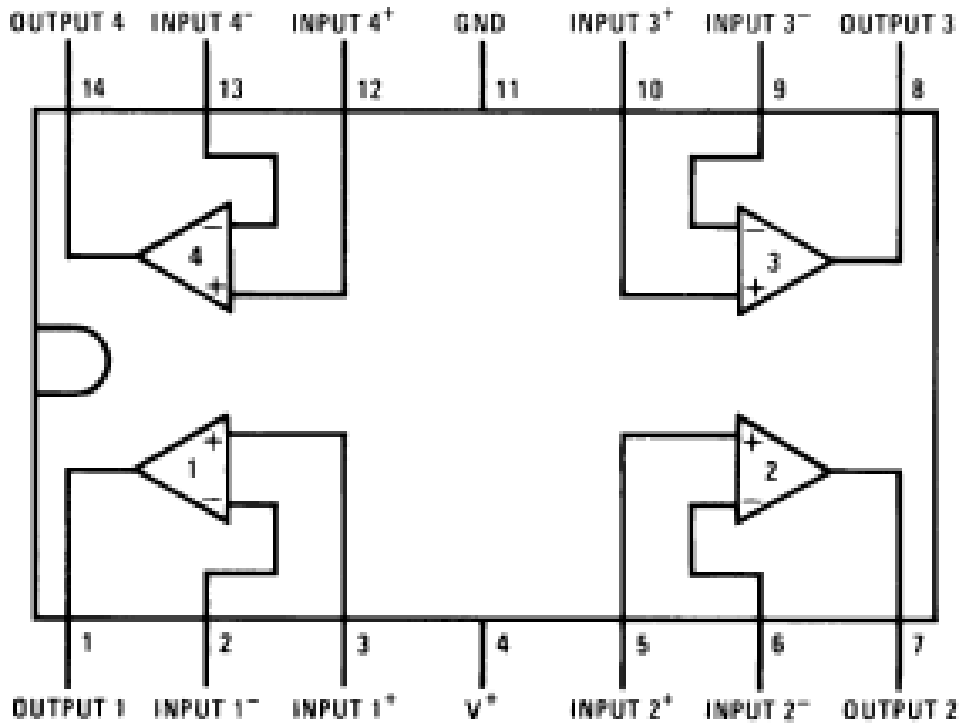

\subsection{IRF Z44N (N-channel MOSFET)}

- $\quad$ Fast switching

- $\quad$ Ease of paralleling

- $\quad$ Simple drive requirement

- $75^{\circ} \mathrm{C}$ Operating Temperature

- Lower Leakage Current: 10mA (Max.) @ VDS=60V

- Lower RDS(ON): 0.020W (Typ.)

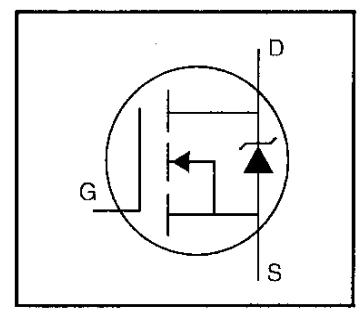

Notes;

a) Repetitive Rating: Pulse Width Limited by Maximum Junction Temperature

b) $\mathrm{L}=0.4 \mathrm{mH}, \mathrm{IAS}=50 \mathrm{~A}, \mathrm{VDD}=25 \mathrm{~V}, \mathrm{RG}=27 \Omega$, Starting $\mathrm{TJ}=25^{\circ} \mathrm{C}$

c) $\quad$ ISD $\leq 50 \mathrm{~A}, \mathrm{di} / \mathrm{dt} \leq 350 \mathrm{~A} / \mu \mathrm{s}, \mathrm{VDD} \leq \mathrm{BVDSS}$, Starting $\mathrm{TJ}=25^{\circ} \mathrm{C}$

d) Pulse Test: Pulse Width $=250 \_$s, Duty Cycle $\leq 2 \%$

e) Essentially Independent of Operating Temperature

\subsection{IRFP250N (N - channel MOSFET)}
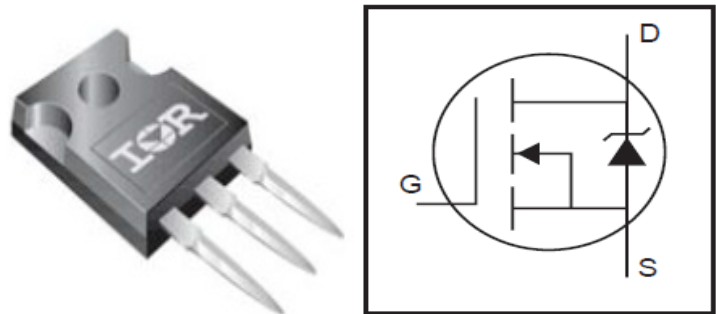

- $\quad$ Fast switching

- $\quad$ Ease of paralleling

- $\quad$ Simple drive requirement

- $\quad 175^{\circ} \mathrm{C}$ Operating Temperature

- Lower Leakage Current: 10mA (Max.)@ $V_{D S S}=$ $200 \mathrm{~V}, I_{D}=30 \mathrm{~A}$

- $\quad R_{D S(O N)}: 0.075 \Omega$

- $\quad$ Simple Drive Requirements

\subsection{C1815 (NPN Transistor)}
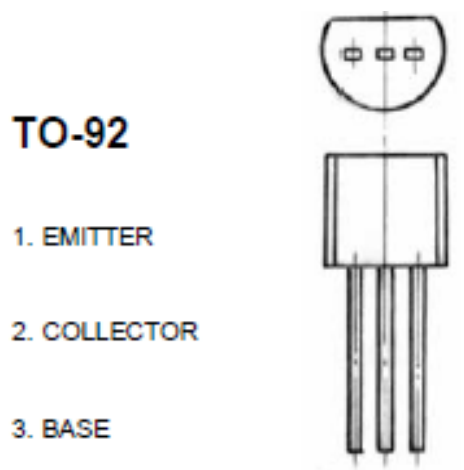

123

- Power dissipation PCM: $0.4 \mathrm{~W}\left(\mathrm{Tamb}=25^{\circ} \mathrm{C}\right)$

- Collector current ICM: 0.15 A

- Collector-base voltage V(BR)CBO: $60 \mathrm{~V}$

- Operating and storage junction temperature range TJ, Tstg: $-55^{\circ} \mathrm{C}$ to $+150^{\circ} \mathrm{C}$

\subsection{MUR460 (Ultra Fast Diode)}

Features:

- Low forward voltage drop.

- High current capability. 
- High reliability.

- High surge current capability.

- Ultra fast 25, 50 nano-second recovery times,

- Maximum recurrent peak reverse voltage: $600 \mathrm{~V}$

\subsection{PWM IC(UC3843)}

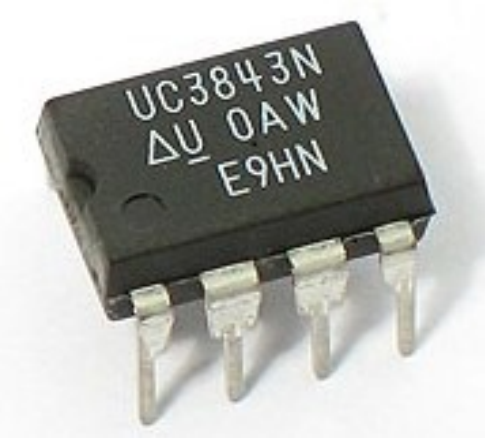

Features:

- Controlled Baseline

- Optimized For Off-line and DC-to-DC Converters

- $\quad$ Low Start-Up Current $(<1 \mathrm{~mA})$

- circuits include under-voltage lockout featuring start

- Automatic Feed Forward Compensation

- Pulse-by-Pulse Current Limiting

- $\quad$ Enhanced Load Response Characteristics

- Under-Voltage Lockout With Hysteresis

- Double Pulse Suppression

- Internally Trimmed Band gap Reference

- $\quad 500-\mathrm{kHz}$ Operation

- Low RO Error Amp

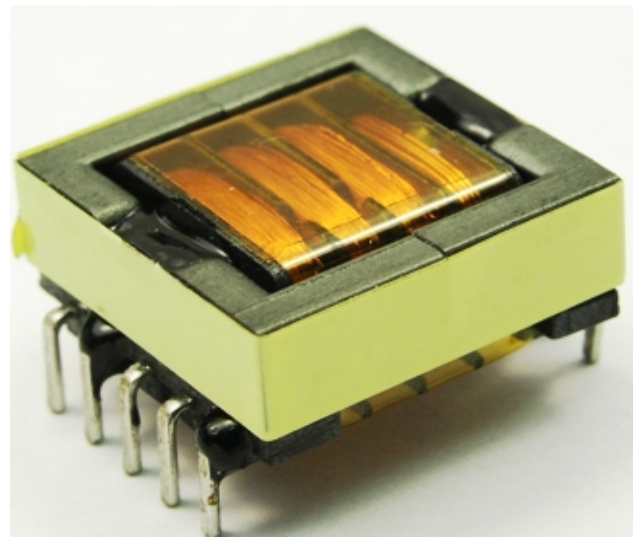

Features:

- EE transformers have a good magnetic,

- Low consume

- To get high function frequency

- High counteract for the obstruction.

- High power frequency $(20 \mathrm{~K}$ to $50 \mathrm{KHz})$

- High power output (1000W)

- Good heat balance

- Customized specifications are competent.

\section{Project Design and Implementation}

In order to execute the endeavor of the project, it is necessary to drive the hardware architecture design based on the understanding of the microcontroller technology. The overall design of the project is shown in the following block diagram:

\subsection{Power Transformer}

\subsection{Block Diagram}

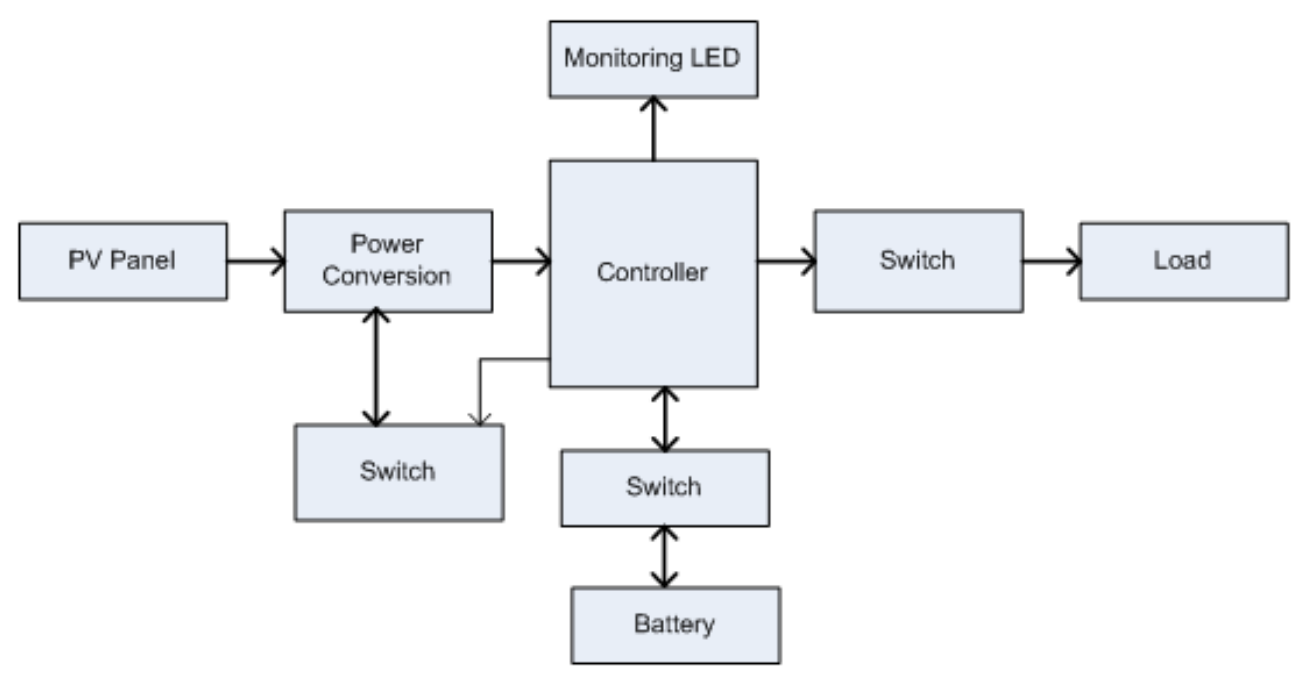

Figure 32. Block diagram of Solar Charge Controller 


\subsection{Schematic Diagram:}

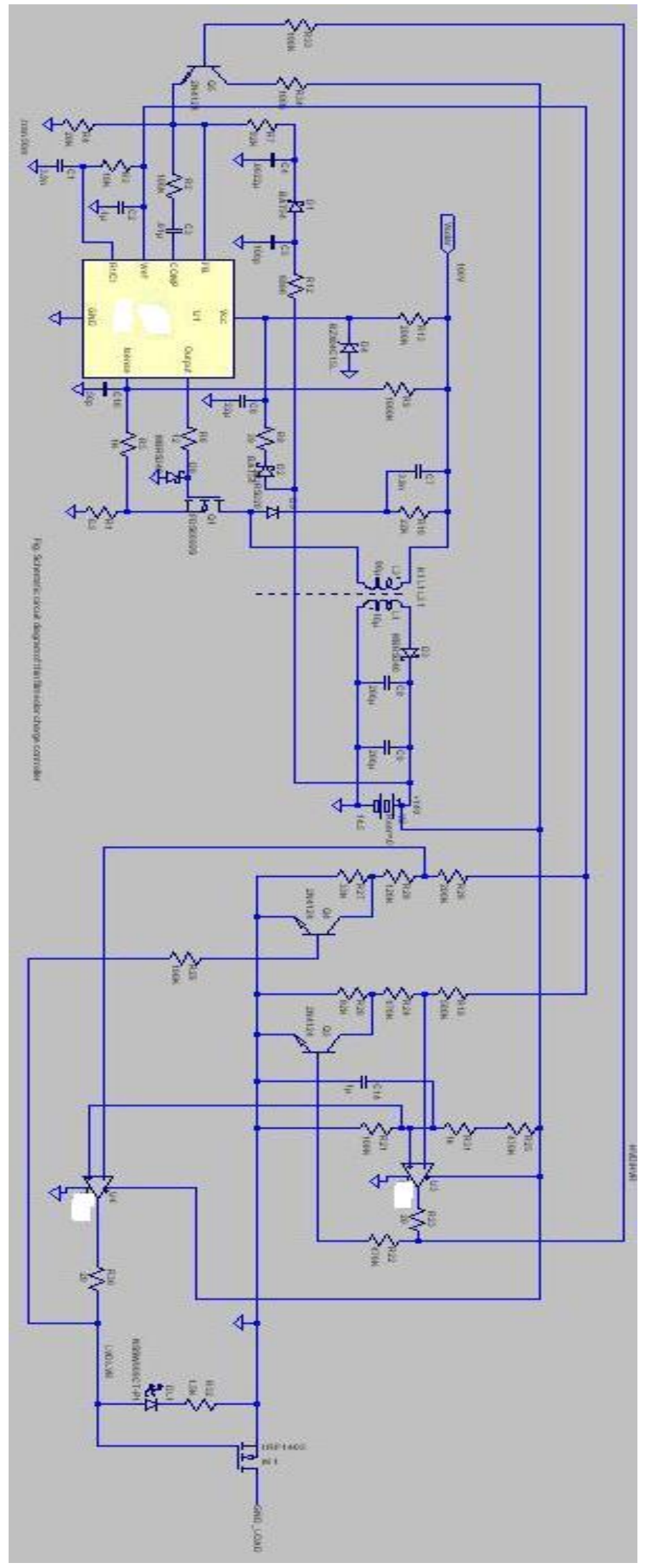

Figure 33. Schematic diagram of whole system 


\subsection{Working Principle}

IC (U1) sense DC high voltage, that voltage comes from solar panel (thin film) through IC pin no-6 (output). It is need to set a duty cycle to drive the MOSFET gate, the value of duty cycles depend on the value of $\mathrm{R}$ (Resistor) and $\mathrm{C}$ (Capacitor). The primary side of transformer (High frequency transformer) is connected with solar panel through the drain of MOSFET. Turn ration is 5:1, between primary sides and secondary side. The power conversion efficiency depend on transformer efficiency, and transformer efficiency depend on transformer designing, types of cores, types wires etc. The pin of FB (feedback) always senses the battery terminal voltage, which signals assist to set the duty cycle of MOSFET and observing the battery terminal voltage. The pin of $I_{\text {sense }}$ always sense the battery charging current, consequently current control function is worked by this pin $\left(I_{\text {sense }}\right)$. The gate signal of MOSFET is followed the Pulse Width Modulation (PWM) mode, that why it's self-power consumptions is very poor. It is required to protection the gate signal of MOSFET from negative voltage to employ the ultra fast forward diode (MUR460).

All controlling signal is generated by op-amplifier IC, that IC number is LM324. It has contained four op-amplifiers, but there has used only two op-amplifiers to generate four signals. Four signals are LVD (Lower voltage disconnects of battery from load connection, that voltage level is $11.6 \mathrm{~V}$ ), LVR (Lower voltage re-connect of battery with load, that voltage level is $12.6 \mathrm{~V}$ ), HVD (Higher voltage disconnect of battery from solar panel, that voltage level is $14.5 \mathrm{~V}$ ), HVR (Higher voltage re-connect of battery with solar panel to charge the battery, that voltage level is $13.2 \mathrm{~V}$ ). Hysteresis voltage level fixes to use the bi-polar transistor and resistor, which is depend on the output of op-amplifier.

MOSFET (IRFP250N) is used for battery charging to convert the voltage of solar panel to follow voltage to current conversion method. The gate signal of MOSFET is controlled by the output of op-amplifier, that signal is push to the pin of com by transistor. It is increasing the charging current to fix the more MOSFET (IRFP250N) in parallel paths and improving others all supporting components.

MOSFET (IRF Z44N) is used to connect with load to follow the normal power transmitted method. The gate signal is controlled by the out of another op-amplifier; this signal is passing through the transistor to the gate of MOSFET. It is increasing the more load to fix the more MOSFET (IRF $\mathrm{Z} 44 \mathrm{~N}$ ) in parallel paths and improving others all supporting components.

\subsubsection{LED indicator}

LCD display consumes high power, so that LCD display can be ignored and in such case LED indicator can be used. There are five LED, connected with all controlled signal of Op-amplifier. LED indicates five different state load, full charge, low battery, charging and normal.

\subsection{Simulation Diagram}

$\mathrm{V}$ (in): Input voltage- $120 \mathrm{~V}$ (Green Color as per diagram). $\mathrm{V}($ out): Out voltage- $14.2 \mathrm{~V}$ (Blue color as per diagram).

Id(Q1): Switching current - 5A (Red color as per diagram) across the MOSFET.

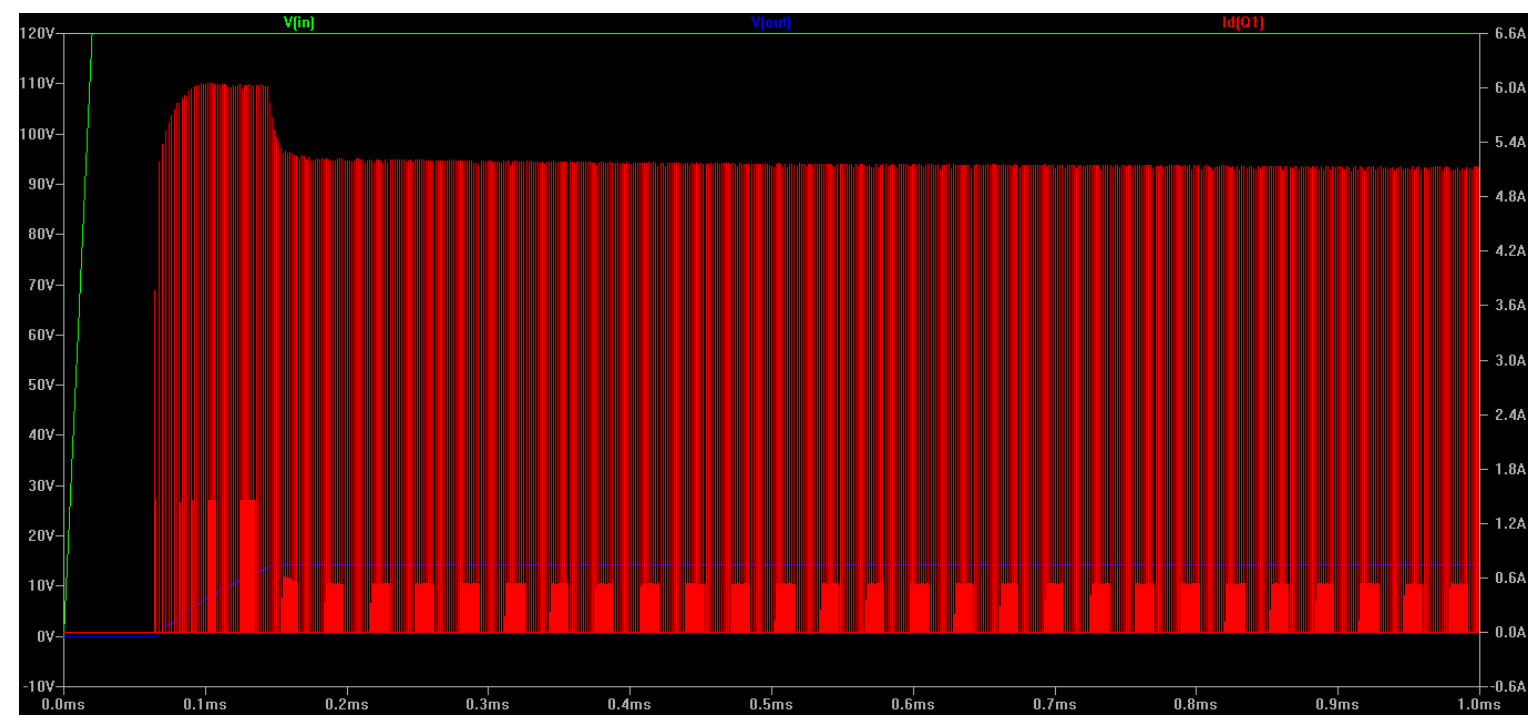

Figure 34. Simulation diagram of major parameters of system 


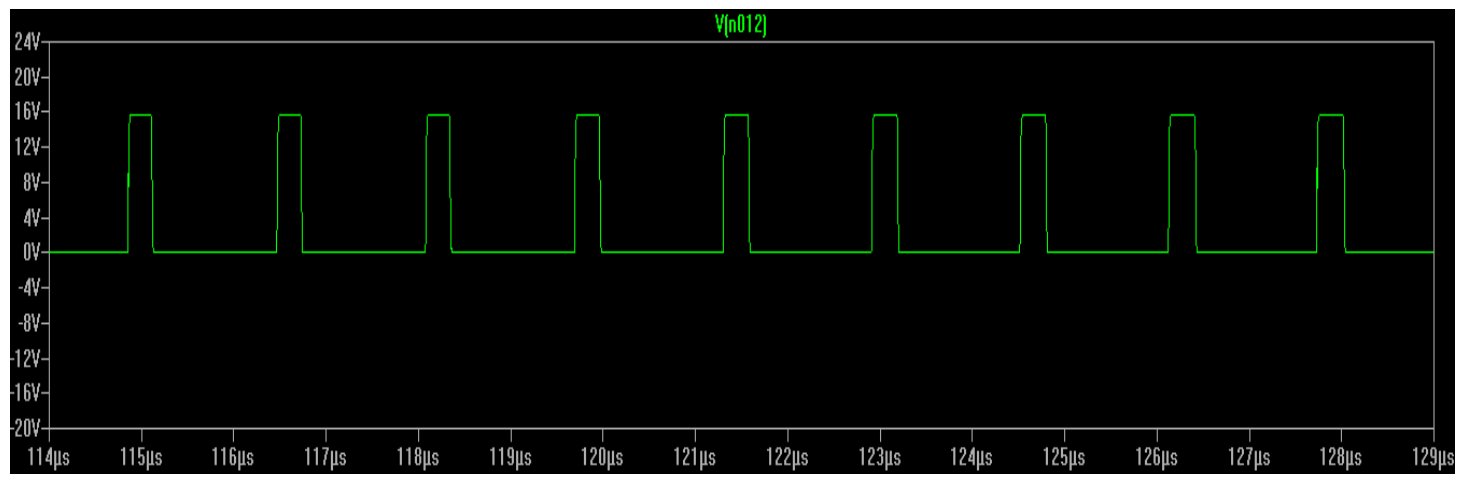

Figure 35. Simulation diagram of duty cycle of switching signal

V(n018): Duty cycle $-378 \mathrm{KHz}$ (Green color as per diagram)

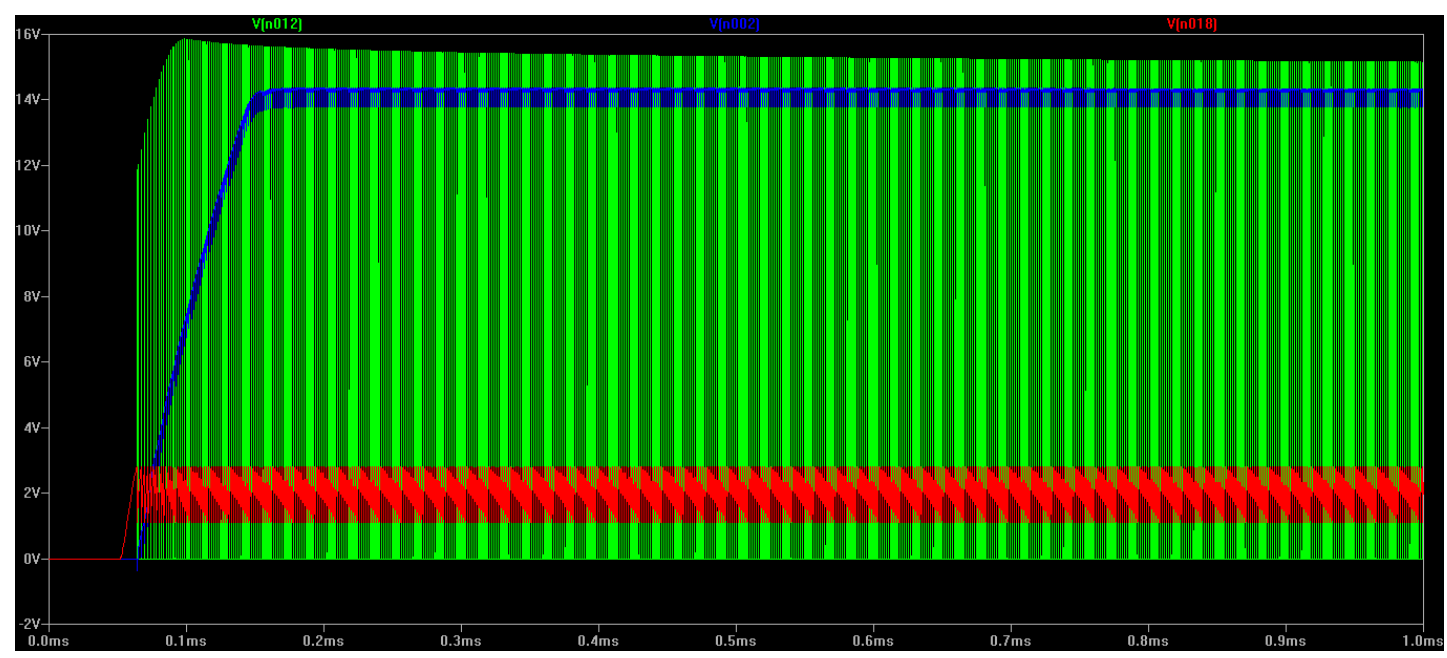

Figure 36. Output voltage shape across the output diode

$\mathrm{V}(\mathrm{n} 002)$ : Output voltage shape across the output diode $-15 \mathrm{~V}$ (Blue Color as per diagram).

$\mathrm{V}(\mathrm{n} 012)$ : Switching voltage shape across the MOSFET (Green color as per diagram).

V(n018): Wave shape of RT/CT- $378 \mathrm{KHz}$

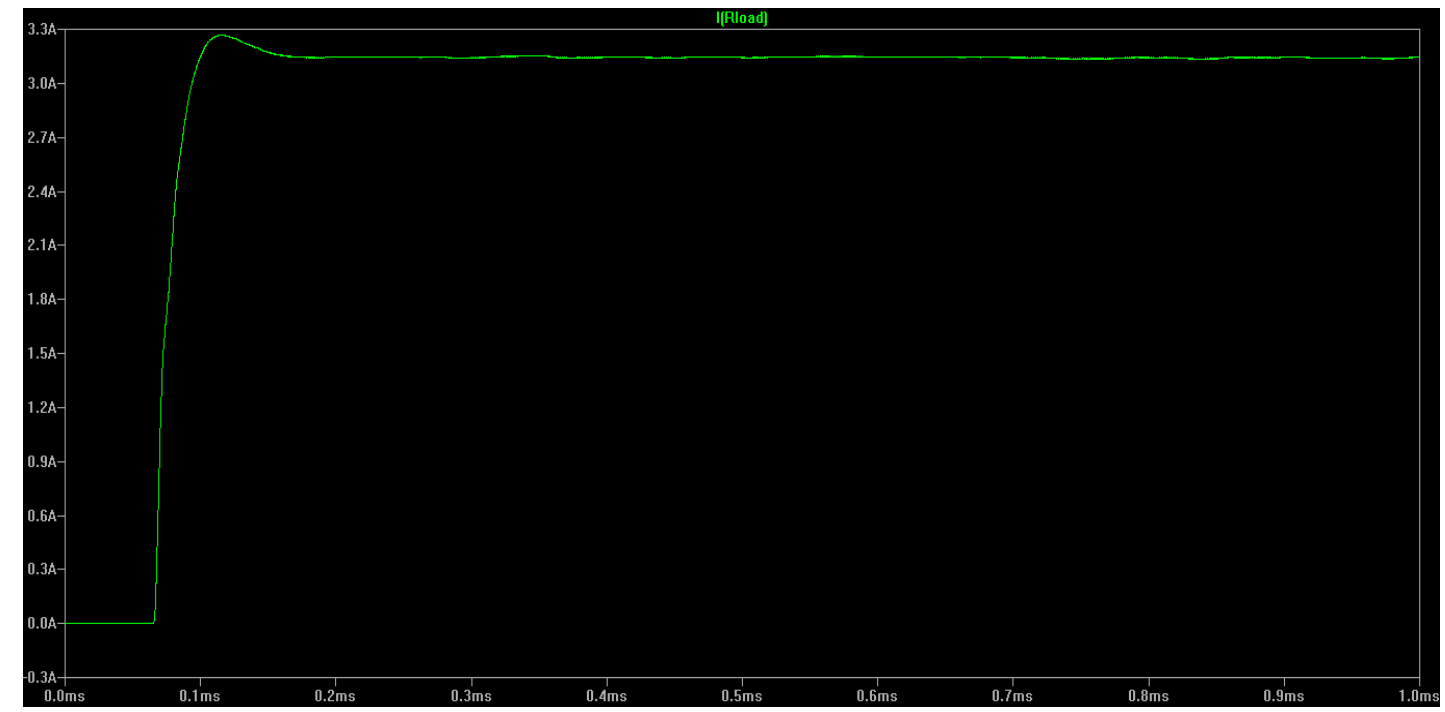

Figure 37. Output current wave shape across the load

I(Rload): Output current across the load- 3.3A (Green color as per diagram) 


\section{Outcomes of the Project}

\subsection{Features of the Device}

The device we developed here has the following features

- Op-amplifier controlled

- Full power output at ambient temperature 40C, de rated output from $40 \mathrm{C}-60 \mathrm{C}$

- A DC load output port rated max 15A

- $\quad$ Three - stage battery charging (bulk, absorption, and float ) with optional temperature compensation

- Various battery types selectable

- An optional battery temperature sensor ensures precise battery charging

- LED to indicate the status of charge

- Reverse current at night

- $\quad$ Complete protection with both PV and battery: over - voltage, reverse polarity, automatic overload protection

- $\quad$ Silent, pulse width modulated (PWM), high efficiency operation

- Configurable auxiliary output

- Switched Mode operation

- $\quad$ Charging topology Buck Mode CV charging - most suited for most Battery chemistries

- Solar charging current up to 10 Amps continuous customized designs are available for higher power ratings

- Load current: Up to 10 Amps continuous customized designs are available for higher power ratings.

- $\quad$ Available in $12 \mathrm{~V} \& 24 \mathrm{~V}$ versions.

- Low voltage Load disconnect: 11.1V.

- Load Reconnect Voltage: 12.1V.

- Night Time current drain: < 10 micro amps.

- Automated frequency selection for wide input voltage range.

- Multiple steps of PWM provided for efficient charging.

- LED indications provided for charge/float.

- Red LED for Low - Voltage indication.

- Uses pulsed float voltage maintenance mode when battery is full $(13.80 \mathrm{~V})$.

- Internal Temperature compensation provided, works well in cold and hot environments.

- RFI (Radio Frequency Interference) suppression, designed to work with radio systems.

- High surge current protection.

- Built in Automated Recovery thermal fuse for protection from excessive load and reverse battery

- Protection - No technician required for maintenance.

- High surge voltage protection.

\subsection{Electrical Specification:}

- $\quad$ Rated Solar input 10 Amps
- Maximum Input 15 Amps

- $\quad$ System Voltage 12 Volts

- Max Solar Panel Voltage 140 Volts

\subsection{Conclusions}

I have chosen to implement the thin film solar charge controller because it seemed the best solution for increasing popularity of solar home system in cheap rate energy solution in off grid area. I am tried to give as much as possible to open an eye on the endless capabilities of such system.

Possible extensions to my project are numerous, and as solar applications become more popular, more efficient circuitry and control will be implemented. First, the chosen op-amplifier has many capabilities which are unnecessary to my project. Therefore, it is a chip with necessary technology which will consume less power in use. Secondly, there will be two switching systems used; one is to disconnect the battery from the solar panel and the other for disconnecting the load from the battery. Thirdly, two different indicator systems, LED is available with the system, out of which the user can choose any one. An improvement to the system can be done through adding an alternative measurement device.

\section{Symbols and Abbreviations}

DC- Direct Current

DOD- Depth of Discharge

FF-Fill Factor

I - Current

ID- Diode Current

Io - Reverse saturation current

Iph- Photocurrent

IR- Infrared

Isc- Short Circuit Current

IV- Current-Voltage

IMMP- Current at maximum power point

MPP- Maximum power point

Pmax- Maximum Power

PV- Photovoltaic

PMPp- Power at Maximum Power point

q-Charge

R- Resistance

Rp- Parallel Resistance

Rs - Series Resistance

SG- Specific Gravity

SOC- state of charge

$\mathrm{T}$ - Temperature

VD- Diode voltage

VMPP- Voltage at Maximum Power Point

Voc- Open circuit Voltage

$\eta$ - Efficiency

$I_{\text {cell- }}$ Cell Current

$V_{\text {in }}$ - Input Voltage

$P_{\text {out- }}$ Output Power 


\section{Acknowledgements}

I would like to thank Md. Shahriar Ahmed Chowdhury, Assistant Professor, Department of Electrical and Electronics Engineering, United International University for his constant guidance throughout my research work. I would also thank my colleague, Mr. Md. Ershadullah, Design Engineer of Solar Intercontinental (SOLARIC) ltd, Mr. Md. Hasnat Jamil, Deputy Manager-Technical, of Solar Intercontinental (SOLARIC) ltd, Md Saddam Hossen, Assistant Engineer of Solar Intercontinental (SOLARIC) ltd, Noormohammad Bhuayan, Test Engineer of Solar Intercontinental (SOLARIC) ltd and my bosom friend, Mr. Mohammad Simon Rahman, who helped me out in my research endeavor.

I would also like to thank my parents and my wife "Saniya Bhuiyan" for inspiring me all the way.

\section{REFERENCES}

[1] http://www.atmel.com

[2] http://www.irf.com/product-info/datasheets/data/irf540n.

[3] http://www.irf.com/product-info/datasheets/data/irf9540n.

[4] http://www.fairchildsemi.com/ds/PN/PN2222

[5] http://www.electrokits.com/Datasheets/7805-Datasheet
[6] http://www.irf.com/product-info/datasheets/data/irfz44n

[7] http://ww1.microchip.com/downloads/en/devicedoc/30444e

[8] http://www.alldatasheet.com/datasheet-pdf/pdf/42343/SEMT $\mathrm{ECH} / 1 \mathrm{~N} 4732 . \mathrm{html}$

[9] http://en.wikipedia.org/wiki/Solar_panel

[10] http://www.ashden.org/solar

[11] http://en.wikipedia.org/wiki/Battery_(electricity)

[12] http://en.wikipedia.org/wiki/Solar_cell

[13] http://www.windsun.com/ChargeControls/ChargeCont

[14] http://en.wikipedia.org/wiki/Pulse-width_modulation

[15] http://www.analog.com/en/content/glp_voltageregs/fca

[16] http://en.wikipedia.org/wiki/Power_MOSFET

[17] http://www.electronics-tutorials.ws/transistor/tran 4.html

[18] http://www.electronics-tutorials.ws/transistor/tran_3.html

[19] http://www.electronics-tutorials.ws/diode/diode_7.html

[20] http://en.wikipedia.org/wiki/Renewable_energy_in_Asia

[21] http://www.top-alternative-energy-sources.com/thin-film-sol ar-cells.html

[22] http://www.circuitstoday.com/thin-film-solar-cell

[23] http://www.bosch-solarenergy.com 